\title{
Urban Tree Health Classification Across Tree Species by Combining Airborne Laser Scanning and Imaging Spectroscopy
}

\author{
Dengkai Chi ${ }^{1, *}$, Jeroen Degerickx ${ }^{2}$,, Kang Yu ${ }^{1,3}$ () and Ben Somers ${ }^{1}$ (C) \\ 1 Department of Earth and Environmental Sciences, University of Leuven, 3001 Heverlee, Belgium; \\ kang.yu@tum.de (K.Y.); ben.somers@kuleuven.be (B.S.) \\ 2 Flemish Institute for Technological Research-VITO NV, Boeretang 200, 2400 Mol, Belgium; \\ jeroen.degerickx@vito.be \\ 3 Department of Life Science Engineering, Technical University of Munich (TUM), 85354 Freising, Germany \\ * Correspondence: dengkai.chi@kuleuven.be
}

Received: 3 July 2020; Accepted: 27 July 2020; Published: 29 July 2020

check for updates

\begin{abstract}
Declining urban tree health can affect critical ecosystem services, such as air quality improvement, temperature moderation, carbon storage, and biodiversity conservation. The application of state-of-the-art remote sensing data to characterize tree health has been widely examined in forest ecosystems. However, such application to urban trees has not yet been fully explored-due to the presence of heterogeneous tree species and backgrounds, severely complicating the classification of tree health using remote sensing information. In this study, tree health was represented by a set of field-assessed tree health indicators (defoliation, discoloration, and a combination thereof), which were classified using airborne laser scanning (ALS) and hyperspectral imagery (HSI) with a Random Forest classifier. Different classification scenarios were established aiming at: (i) Comparing the performance of ALS data, HSI and their combination, and (ii) examining to what extent tree species mixtures affect classification accuracy. Our results show that although the predictive power of ALS and HSI indices varied between tree species and tree health indicators, overall ALS indices performed better. The combined use of both ALS and HSI indices results in the highest accuracy, with weighted kappa coefficients $(\mathrm{Kc})$ ranging from 0.53 to 0.79 and overall accuracy ranging from 0.81 to 0.89 . Overall, the most informative remote sensing indices indicating urban tree health are ALS indices related to point density, tree size, and shape, and HSI indices associated with chlorophyll absorption. Our results further indicate that a species-specific modelling approach is advisable (Kc points improved by 0.07 on average compared with a mixed species modelling approach). Our study constitutes a basis for future urban tree health monitoring, which will enable managers to guide early remediation management.
\end{abstract}

Keywords: defoliation; discoloration; street trees; airborne LiDAR; airborne hyperspectral data; random forest

\section{Introduction}

Urban trees play a crucial role in mitigating urban environmental problems by providing a range of crucial ecosystem services, e.g., reducing air pollution, moderating temperatures, reducing stormwater runoff and storing carbon [1,2]. Increased recognition of the high value of trees to urban environments has encouraged municipal tree planting programs around the world [3]. Although it has been reported that trees at higher, cooler latitudes may benefit from urban warming [4,5], urban trees, in general, are under continuous pressure from environmental problems typical to the urban environment. Paved surfaces modify the moisture dynamics of underlying soils [6], increasing the risk of water stress for trees, and therefore, their susceptibility to pests [7-9]. The reduced soil aeration and limited rooting 
space caused by extensive impervious surfaces result in a general poor tree health status [10]. At the same time, soil contamination, salinization and acidification are widely distributed in urban areas, negatively affecting the development of trees [11-13]. In addition, air pollutants in urban areas have been widely reported for their adverse effects on tree health [14-16]. In short, the harsh environmental conditions in cities are reducing tree health and thereby jeopardizing important ecosystem services provided by trees and causing important safety issues [17], which eventually even threaten public health [18]. In this context, it is important for urban green managers to collect reliable information on tree health as a basis for early remediation management, such as targeted irrigation, pruning, and/or salvation logging [19].

Defoliation and discoloration, visually expressed via leaf loss and changes in leaf color, respectively, are two quantitative and generally adopted tree health indicators, integrating across many diagnoses [20,21]. Damage, as a function of defoliation and discoloration, has been used to indicate the overall tree health condition [22,23]. Traditional visual tree assessment (VTA) methods [20] conducted by trained tree experts, has formed the basis for monitoring trees towards forest planning and decision making in many countries [24,25]. Tree health assessment conducted using the VTA method is, however, limited in spatial coverage due to labor constraints of tree experts. Remote sensing methods have been extensively proven to bear the potential of solving these problems by providing accurate, spatially explicit, and detailed information on tree health [26-29].

Yet, so far, current efforts for tree health assessment using remote sensing mainly focused on forest ecosystems. High-resolution airborne and satellite imagery have been used for forest tree mortality and tree health assessment on both the individual tree canopy scale $[26,29,30]$ and the image pixel scale [31-34]. Airborne hyperspectral imagery (HSI), providing optical information in high spectral detail, has been extensively applied to provide both biochemical and structural information for identifying tree health [27,28,35-39]. Airborne laser scanning (ALS) provides additional opportunities for monitoring tree health [26,40-42]. Besides structural information that can directly be linked to tree health, ALS also facilitates individual tree canopy segmentation, which is the basis for individual or object-based tree health assessment $[43,44]$. In forest research, a few studies have integrated the information derived from ALS and airborne HSI with field assessments to monitor forest health. Shendryk et al. [30] used this approach to assess tree crown dieback and transparency ratios in a Eucalypt forest and their results showed a higher accuracy with the combined use of the two data sources compared to only using one. A similar finding was also reported in Meng et al. [29], in which the authors mapped forest canopy defoliation caused by herbivorous insects at the individual tree level using a combination of ALS and airborne HSI.

In urban settings, efforts on tree health assessment using high-resolution remote sensing data have been undertaken recently. For example, Fang et al. [45] evaluated the potential of WorldView-3 satellite images to detect field-measured tree health condition classes and found NDVI1 (defined as the normalized ratio of the red and the near-infrared bands (770-895 nm)) on a July image to show the strongest statistical difference between trees with good, fair, or poor health condition. However, the combination of ALS and airborne HSI based tree health classification in urban settings remains strongly underexplored. In two separate studies, Näsi et al. [19,38] showed the potential of UAV-based photogrammetry and hyperspectral imaging for mapping bark beetle damage at tree level in an urban forest. Most existing tree health studies focused either on assessing tree crown defoliation [29,30,37] or the overall tree health condition $[26,27,38]$, while attention to tree crown discoloration remained limited. In response to this, Degerickx et al. [46] conducted an object-based tree health classification based on chlorophyll content (discoloration) and leaf area index (defoliation) derived from airborne HSI. Whereas, ALS data was used for the segmentation of individual tree crowns, it remains unclear to what extent structural information derived from ALS data can be used, either alone or in combination with HSI, to assess the individual aspects of urban tree health (i.e., discoloration and defoliation) and overall tree health condition. 
The heterogeneity of tree species found in urban environments further complicates urban tree health mapping. Xiao and McPherson [47] used the NDVI for a binary classification of healthy vs. unhealthy trees at the campus of the University of California, Davis. They found it was hard to map tree health across different species or in places where many tree species co-existed. For example, some healthy, well-grown conifer trees had the same NDVI value as an unhealthy broadleaf deciduous tree. Indeed, tree characteristics (e.g., leaf size, water and pigment content and tree structure) may vary among healthy trees of different species, and as a result, serious tree health classification errors could be produced when applying the same classification model across different tree species. Therefore, there is a clear need to identify the most informative spectral and structural indices related to tree health across species.

The overall aim of this study was to assess the potential of the synergetic use of ALS and airborne HSI for urban tree health mapping. To this end, a tree health classification procedure using a Random Forest (RF) classifier with input indices derived from the two data sets was established. In particular, classification was conducted for three dominant broad-leaved species in Brussels, Belgium. Based on the presented research progress on urban tree health, and known hurdles for the widespread adoption of high-resolution remote sensing data in urban tree health assessment, we defined three specific research questions: (1) What are the differences in the predictive performance of ALS data, airborne HSI and their combination for different aspects of urban tree health (i.e., defoliation, discoloration and their combination, i.e., damage)? (2) To what extent do tree species mixtures affect the accuracy of urban tree health classification? (3) Which input indices derived from ALS and airborne HSI are most important/informative for tree health classification?

\section{Materials and Methods}

\subsection{Airborne Laser Scanning and Hyperspectral Imagery}

Airborne laser scanning (ALS) data, covering the eastern part of Brussels, Belgium (Figure 1), was collected on 11 June 2015, by Aerodata Surveys Nederland BV using a full-waveform sensor with a wavelength of $1550 \mathrm{~nm}$. The sensor was mounted on a plane with an altitude of $3000 \mathrm{~m}$ above the ground. The average point density was 15 points $/ \mathrm{m}^{2}$. After removing noise points, a digital terrain model (DTM), digital surface model (DSM) and normalized digital surface model (nDSM) were derived using LAStools software (http://lastools.org) with a spatial resolution of $0.25 \mathrm{~m}$. In addition, a normalized ALS point cloud was obtained by calculating the height difference between the original ALS points without noise points and the DTM layer, which was subsequently used for deriving indices relevant to tree health (see Section 2.4).

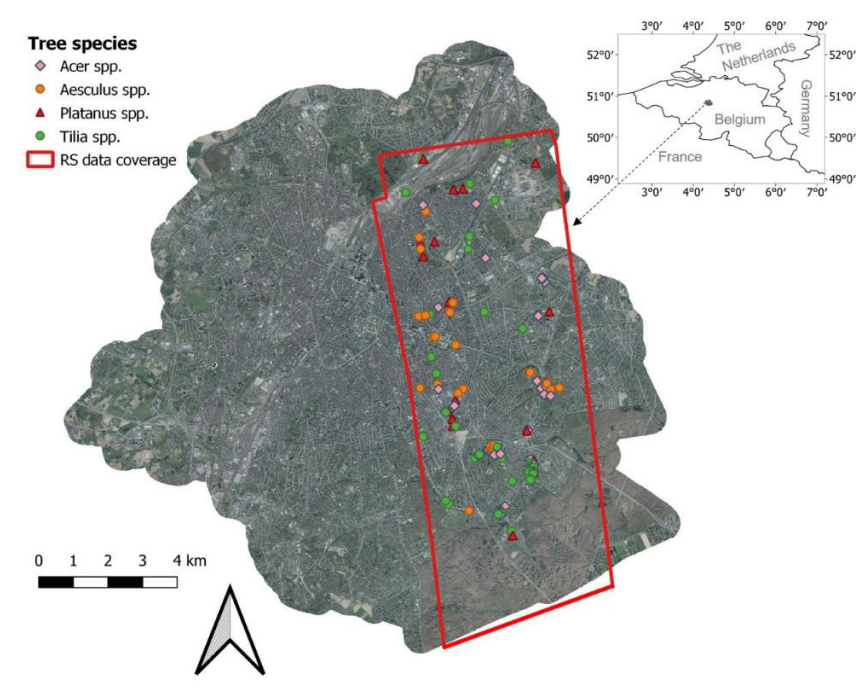

Figure 1. Remote sensing data coverage and locations of sampled trees. 
Airborne hyperspectral imagery (HSI) over the same area was acquired on 30 June 2015, using the Airborne Prism Experiment (APEX) sensor mounted on a plane, at a flying height of about $3600 \mathrm{~m}$. An automated processing chain at the Flemish Institute for Technological Research was used to preprocess the imagery [48]. The radiometric, spectral, and geometric calibration was performed by means of calibration cubes generated from data measured and collected on the APEX Calibration Home Base (CHB) hosted at DLR Oberpfaffenhofen, Germany [49]. To reduce smile effects (i.e., the central wavelength depends slightly on the column pixel location) and spectral instabilities caused by pressure and/or temperature variations, an in-flight spectral wavelength shift analysis was conducted on the basis of atmospheric absorption features to reassign new central wavelengths to each pixel. The geometric correction was performed via direct georeferencing. Input data from the sensor's GPS/IMU, boresight correction data and the derived DTM/DSM from ALS data were further used during the geometric correction process. The data were then projected to a Belgium Lambert 72 coordinate system. The atmospheric correction was conducted using a MODTRAN4 radiative transfer model $[50,51]$. The resulting spectral data comprised 285 spectral bands distributed across the $412-2431 \mathrm{~nm}$ spectral range, with a spatial resolution of $2 \mathrm{~m}$. Atmospheric absorption bands $(412-450 \mathrm{~nm}$, $1340-1500 \mathrm{~nm}, 1760-2020 \mathrm{~nm}$, and 2350-2431 nm) were then excluded from further analysis.

\subsection{Field Data Collection}

Collection of field data was carried out in June 2015, coinciding with the remote sensing data acquisitions, for a total of 131 trees. The trees were randomly selected across the study area (Figure 1) and covered a range of different sizes and health status. Tree height, diameter at breast height $(1.37 \mathrm{~m} ; \mathrm{DBH})$ and crown diameter in a north-south direction and west-east direction were recorded. The health status was scored by two independent researchers using the FAO (The Food and Agriculture Organization) guidelines for the assessment of forest crown conditions [22,23]. Crown defoliation and discoloration of each tree were separately estimated on a 0-3 score, and the damage scores were obtained by combining the defoliation and discoloration scores according to Lakatos et al. [22] (Table 1). Therefore, each tree was labeled with three scores indicating the classes of defoliation, discoloration and damage, respectively. Because of the rare occurrence of trees with a crown defoliation or discoloration score of 3 , we decided to merge these trees into class 2 . Therefore, class 2 in this paper corresponds to trees with more than $25 \%$ crown defoliation or discoloration. The final distribution of tree health scores is shown in Figure A1. We focused on the four most dominant tree genera in Brussels, including Acer (mainly A. pseudoplatanus and A. platanoides; $\mathrm{n}=37$ ), Aesculus (A. hippocastanum; $\mathrm{n}=34$ ), Platanus (P. $x$ acerifolia; $\mathrm{n}=18$ ) and Tilia (mainly T. $x$ euchlora and T. $x$ europaea; $\mathrm{n}=42$ ). Four tree health datasets were created for tree health classification (see Section 2.6.1): (1) Acer trees, (2) Aesculus trees, (3) Tilia trees, and (4) all the 131 trees. Platanus trees were not used as an independent dataset, due to the small sample size.

Table 1. Damage scores by combining defoliation and discoloration scores (modified according to Lakatos et al. [22]).

\begin{tabular}{ccccc}
\hline \multirow{2}{*}{ Defoliation } & & \multicolumn{3}{c}{ Discoloration } \\
\cline { 3 - 5 } & & $\mathbf{0 - 1 0 \%}$ & $\mathbf{1 0 - 2 5 \%}$ & $\mathbf{2 5 \%}$ \\
\cline { 2 - 5 } & & $\mathbf{0}$ & $\mathbf{1}$ & $\mathbf{2}$ \\
\hline $0-10 \%$ & 0 & 0 & 0 & 1 \\
$10-25 \%$ & 1 & 1 & 1 & 2 \\
$>25 \%$ & 2 & 2 & 2 & 2 \\
\hline
\end{tabular}

\subsection{Tree Crown Identification and Delineation}

We utilized an object-based classification procedure described in Degerickx et al. [46] to isolate tree canopies from non-tree objects. The main input data included a rasterized tree index [52] with a 
spatial resolution of $0.25 \mathrm{~m}$ generated using the normalized ALS point cloud, the nDSM and a NDVI image calculated from the HSI. The rasterized tree index was used to initially isolate tree canopies, and non-tree objects and the NDVI image was subsequently used to remove the building edges which were misclassified as tree canopies. Please refer to Degerickx et al. [46] for more details about the tree crown identification algorithm. The correct tree objects were then delineated using a watershed segmentation algorithm to obtain individual tree crowns. Tree crown identification and delineation were conducted in eCognition 9.4 (http://www.ecognition.com/).

To assess the accuracy of automatically delineated tree crowns (resulting layer), we manually drew tree crown polygons (reference layer) for randomly selected 40 trees (10 trees per tree species) based on visual interpretation of the nDSM and ortho-photo images with $7.5 \mathrm{~cm}$ spatial resolution. The overlapping proportions (OPs) between the polygon sets calculated by setting each of them as the basis layer, respectively (i.e., $\mathrm{OP}_{\text {ref }}$ and $\mathrm{OP}_{\text {result }}$ ) were used to assess the accuracy of the delineation algorithm [53].

\subsection{Calculation of Indices Derived from Airborne Laser Scanning Data}

\subsubsection{ALS Intensity Normalization}

ALS point cloud intensity has been recommended as important information for forest condition assessment [54]. The intensity values recorded by the ALS system correspond to the amount of energy reflected from the target to the laser sensor and relate to radiometric properties of the target. Other factors, such as environmental factors, angle of incidence, and the sensor-target distance (or range) also have an effect on the intensity [55]. Therefore, intensity normalization is important for successful tree health detection using ALS data. In this study, we used a distance-based approach [56] (Equation (1)) to normalize the intensity data, which are on an 8-bit scale. This method is based on the fact that the distance from the target to the ALS sensor and reflectivity of the target are the two important factors directly affecting the intensity values.

$$
I_{\text {normalized }}=I \cdot R^{2} / R_{r e f}^{2}
$$

where $I_{\text {normalized }}$ is the normalized intensity value, $I$ is the raw intensity value, $R$ is the distance between the ALS sensor and the point, and $R_{r e f}$ is the reference distance (average flight altitude). Ideally, $R$ is calculated using the GPS time when the point was recorded combined with the plane position assigned to the point. Due to lack of information on flight paths, we used an alternative method to calculate $R$, which is the difference of the average flight height and the height of each point [57].

\subsubsection{ALS Points Classification}

ALS points for each tree were isolated using the automatically delineated tree crown polygon. To accurately calculate indices from ALS points, we developed a procedure to classify the normalized ALS points (cf. Section 2.1) for each tree as ground points, trunk points (under the tree crown) and crown points (the points within a tree crown). The crown points were further classified as leaf points and points from woody materials. First, the normalized ALS points with a height below $1 \mathrm{~m}$ were labeled as ground points and the remaining points were regarded as non-ground points. Next, the non-ground points for each tree were sliced into bins with a height of $0.2 \mathrm{~m}$ along the z-axis. Bins having a 2D projected area, which was calculated based on the $x$ and $y$ coordinates of the outmost points within the bin, smaller than a threshold were regarded as part of the trunk [58] (Figure 2). The threshold value in this study was set in a dynamic way, matching the basal area calculated based on the DBH measured in the field. The points in bins with a 2D projected area larger than the calculated basal area were labeled as canopy points. Finally, the canopy points for each tree were classified as leaf points or woody materials points based on the values of range-corrected intensity as many researchers found the intensity of ALS pulses reflected from vegetation foliage and woody materials to be different $[59,60]$. Based on the histogram distribution of the intensities of extracted trunk points, 
we found ALS pulses at $1550 \mathrm{~nm}$ reflected weakly from woody materials. Therefore, canopy points with an intensity higher than 134DN (95th percentile intensity value of all trunk points) were classified as leaf points and the remaining points were regarded as woody materials. This particular intensity threshold closely matches the threshold of 130DN determined by Shendryk et al. [30].

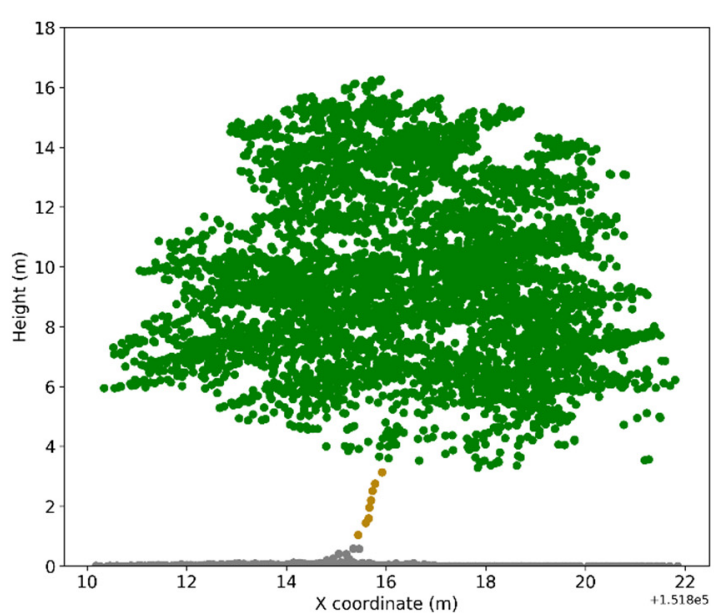

(a)

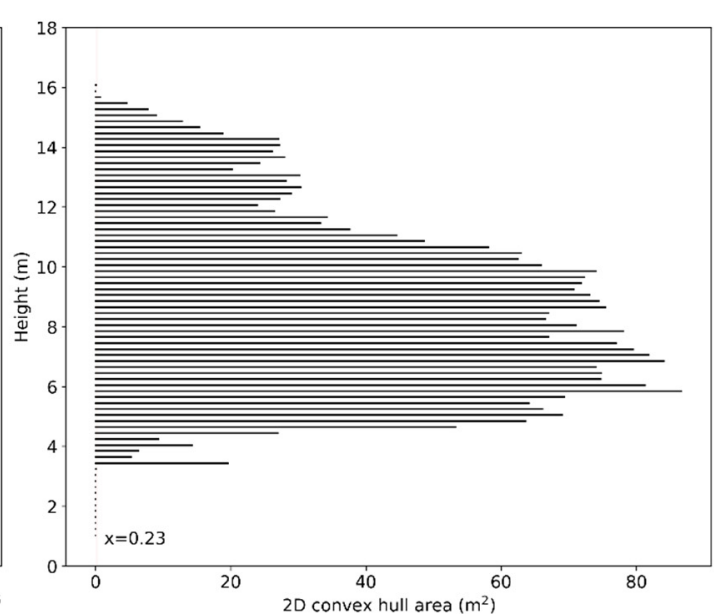

(b)

Figure 2. Illustration of trunk points extraction: (a) Normalized ALS points; (b) 2D convex hull area calculated for points in each bin with a height of $0.2 \mathrm{~m}$. The threshold (basal area) for extracting trunk points of the demonstrated tree is $0.23 \mathrm{~m}^{2}$. Points in bins with a $2 \mathrm{D}$ convex hull area smaller than $0.23 \mathrm{~m}^{2}$ and higher than $1 \mathrm{~m}$ were labeled as trunk points (in brown). Note that points from upper crown were excluded to avoid misclassification.

\subsubsection{Deriving Tree Crown Specific ALS Indices}

For each tree, 140 ALS indices, including height indices, intensity indices, point density indices, tree size and shape indices, were calculated (Table 2) from the ALS point cloud. The selection of indices was based on their known relevance for tree health assessment [26,29,30,54].

Table 2. Indices calculated from airborne laser scanning point cloud ( $H$ is the height of an individual point, and $I$ is the range-corrected intensity of an individual point).

\begin{tabular}{|c|c|}
\hline ALS Indices & Description \\
\hline \multicolumn{2}{|r|}{ Height Indices } \\
\hline Hmin & Minimum height of crown points \\
\hline Hmax & Maximum height of the tree points \\
\hline Hran & Difference between Hmax and Hmin \\
\hline Havg & Average height of the tree points \\
\hline Hstd & Standard deviation of the height of the tree points \\
\hline Hcv & Coefficient of variation of the height of the tree points \\
\hline Hvar & Variance of the height of the tree points \\
\hline Hske & Skewness of the height of the tree points \\
\hline Hkur & Kurtosis of the height of the tree points \\
\hline Нр05-Hр95 & Height percentiles (i.e., $5,10, \ldots, 95)$ of tree points \\
\hline Haad & Average Absolute Deviation of the height of the tree points: mean $(\mathrm{abs}(\mathrm{H}-\mathrm{Havg}))$ \\
\hline Hmad & Median Absolute Deviation of the height of the tree points: median(abs $(\mathrm{H}-\mathrm{Hp} 50))$ \\
\hline Hipr & Inter-Percentile Range of the height of the tree points: $\mathrm{Hp} 75-\mathrm{Hp} 25$ \\
\hline Hravg & Ratio of the number of tree points above Havg to the number of all tree points \\
\hline $\begin{array}{l}\text { Hrmed } \\
\text { Hqav }\end{array}$ & $\begin{array}{c}\text { Ratio of the number of tree points above } H p 50 \text { to the number of all tree points } \\
\text { Average of the quadratic height of tree points }\end{array}$ \\
\hline$H f 10-H f 90$ & $\begin{array}{l}\text { Fraction of tree points between the } n \text {th (i.e., } 10,20, \ldots, 90) \text { percentile height } \\
\text { and } \operatorname{Hax}\end{array}$ \\
\hline Hm0_10-Hm90_100 & $\begin{array}{l}\text { Average height of tree points between intervals of the height percentiles } \\
\text { (i.e., } 0-10,10-20, \ldots, 90-100 \text { ) }\end{array}$ \\
\hline
\end{tabular}


Table 2. Cont.

\begin{tabular}{|c|c|}
\hline ALS Indices & Description \\
\hline \multirow{3}{*}{ Hm0_10n-Hm90_100n } & Height Indices \\
\hline & $\begin{array}{l}\text { Average height of tree points between intervals of the height percentiles (i.e., } 0-10 \text {, } \\
\qquad 10-20, \ldots, 90-100) \text { normalized by Havg }\end{array}$ \\
\hline & Intensity Indices \\
\hline Iam & Average intensity of tree laser returns above $\mathrm{Hp} 50$ \\
\hline $\mathrm{Ibm}$ & Average intensity of tree laser returns below $\mathrm{Hp} 50$ \\
\hline Imin & Minimum intensity of tree laser returns \\
\hline $\operatorname{Imax}$ & Maximum intensity of tree laser returns \\
\hline Iran & Difference between Imax and Imin \\
\hline $\operatorname{Iavg}$ & Average intensity of tree laser returns \\
\hline Istd & Standard deviation of intensity of tree laser returns \\
\hline Icv & Coefficient of variation of intensity of tree laser returns \\
\hline Iske & Skewness of intensity of tree laser returns \\
\hline Ikur & Kurtosis of intensity of tree laser returns \\
\hline Iaad & Average Absolute Deviation of intensity of tree laser returns: mean(abs(I-Iavg)) \\
\hline Imad & Median Absolute Deviation of intensity of tree laser returns: median(abs(I-Ip50)) \\
\hline Ip05-Ip95 & Intensity percentiles (i.e., $5,10, \ldots, 95)$ of tree laser returns \\
\hline Iipr & Inter-Percentile Range of intensity of tree laser returns: Ip $75-\operatorname{Ip} 25$ \\
\hline Ivar & Variance of intensity of tree laser returns \\
\hline $\operatorname{Iravg}$ & $\begin{array}{c}\text { Ratio of the number of tree laser returns with an intensity higher than Iavg to the } \\
\text { number of all tree laser returns }\end{array}$ \\
\hline Irmed & $\begin{array}{l}\text { Ratio of the number of tree laser returns with an intensity higher than Ip50 to the } \\
\text { number of all tree laser returns }\end{array}$ \\
\hline Iqav & Average of the quadratic intensity of tree laser returns \\
\hline If10-If90 & $\begin{array}{c}\text { Fraction of tree laser returns between the nth (i.e., } 10,20, \ldots, 90) \text { percentile } r \\
\text { intensity and } \operatorname{Imax}\end{array}$ \\
\hline Im0_10-Im90_100 & $\begin{array}{l}\text { Average intensity of tree laser returns between intervals of intensity percentiles } \\
\qquad \text { (i.e., } 0-10,10-20, \ldots, 90-100)\end{array}$ \\
\hline Im0_10n-Im90_100n & $\begin{array}{l}\text { Average intensity of tree laser returns between intervals of intensity percentiles } \\
\text { (i.e., } 0-10,10-20, \ldots, 90-100) \text { normalized by Iavg } \\
\text { Point Density Indices }\end{array}$ \\
\hline$D E N$ & Ratio of number of crown points from leaves to 3D convex hull of all points \\
\hline CNT & Total number of points for each tree \\
\hline EWI & $\begin{array}{c}\text { Ratio of number of crown points from woody components to the number of } \\
\text { crown points from leaves }\end{array}$ \\
\hline FC & $\begin{array}{c}\text { Ratio of number of first laser returns from tree crowns to the number of all first } \\
\text { laser returns }\end{array}$ \\
\hline CT & Ratio of number of crown points to the number of all tree points \\
\hline$F G$ & $\begin{array}{c}\text { Ratio of number of first laser returns from ground to the number of all first } \\
\text { laser returns }\end{array}$ \\
\hline \multirow[t]{2}{*}{ GT } & Ratio of number of ground points to the number of all tree points \\
\hline & Tree Size and Shape Indices \\
\hline CRR & Canopy Relief Ratio of tree points: $(\operatorname{Havg}-H \min ) /(\operatorname{Hmax}-H \min )$ \\
\hline $\mathrm{RCHVH}$ & Ratio of 3D convex hull volume of all points to Hmax cubed \\
\hline$C A$ & $\begin{array}{l}\text { Area of each tree crown (calculated by buffering each airborne laser scanning } \\
\text { (ALS) point by } 0.25 \mathrm{~m} \text { ) }\end{array}$ \\
\hline$C D$ & Diameter of each tree crown \\
\hline WH & Ratio of $C D$ to $H \max$ \\
\hline
\end{tabular}

\subsection{Calculation of Indices Derived from Airborne Hyperspectral Imagery}

\subsubsection{Pixel Selection}

As there is high possibility that HSI pixels at the border of tree crown polygons were contaminated by background materials (e.g., impervious surfaces, shrubs and grass), the border pixels were removed before extracting tree crown specific pixels. In addition, we used a threshold of $75 \%$ of the maximum brightness within the tree crown to further remove shaded crown pixels. The pixel selection procedure remained at least three pixels within the tree crown for $95 \%$ of trees. The remaining HSI pixels contained within the tree crown polygon were used for further spectral characterization of individual trees. 


\subsubsection{Deriving Tree Crown Specific HSI Indices}

Building upon previous tree health studies $[27,28,37]$, we calculated 61 existing spectral indices (HSI indices; Table 3) for each selected HSI pixel enclosed within the automatically delineated tree crown. The HSI indices are associated with the absorption features of chlorophyll, carotenoid, anthocyanin, xanthophyll, water and tree structure. Subsequently, each tree crown specific HSI index was averaged per tree crown.

Table 3. Indices calculated from airborne hyperspectral imagery.

\begin{tabular}{|c|c|c|}
\hline Spectral Indices Related to & Abbreviation & Reference \\
\hline \multicolumn{3}{|l|}{ Chlorophyll } \\
\hline Chlorophyll Absorption in Reflectance Index & CARI & [61] \\
\hline Chlorophyll Content Index & $C C I$ & [62] \\
\hline Chlorophyll Index Red Edge & CI & [63] \\
\hline First-order derivative green vegetation index with local baseline & $1 D L \_D G V I$ & [64] \\
\hline Gitelson and Merzlyak indices 1 & GM1 & [65] \\
\hline Gitelson and Merzlyak indices 2 & GM2 & [65] \\
\hline MERIS Terrestrial Chlorophyll Index & MTCI & [66] \\
\hline Modified CARI & MCARI & [61] \\
\hline Normalized Area Over Reflectance Curve & NAOC & [67] \\
\hline Normalized Difference Red Edge & NDRE & [68] \\
\hline Normalized Difference Vegetation Index & NDVI & [69] \\
\hline Spectral index developed using the OMNBR approach & ICHL & [46] \\
\hline Pigment Specific Normalized Difference & PSNDc & [70] \\
\hline Pigment Specific Simple Ratio Chlorophyll a & PSSRa & [70] \\
\hline Pigment Specific Simple Ratio Chlorophyll b & $P S S R b$ & [70] \\
\hline Reflectance Band Ratio Index & DattNIRCabCx $+c$ & [71] \\
\hline Vogelmann red edge index 1 & VOG1 & [72] \\
\hline Vogelmann red edge index 2 & VOG2 & [72] \\
\hline Vogelmann red edge index 3 & VOG3 & [72] \\
\hline Zarco and Miller & $Z M$ & [73] \\
\hline Red edge position & REP & [74] \\
\hline Green Normalized Difference Vegetation Index & GNDVI & [75] \\
\hline Ratio & DI1 & [76] \\
\hline Green Optimized Soil Adjusted Vegetation Index & GOSAVI & [77] \\
\hline Transformed Chlorophyll Absorption in Reflectance Index & TCARI & [63] \\
\hline \multicolumn{3}{|l|}{ Carotenoid } \\
\hline Plant Senescencing Reflectance Index & PSRI & [78] \\
\hline Pigment Specific Simple Ratio Carotenoids & PSRRc & [70] \\
\hline Carotenoid Reflectance Index & $C R I_{550 \_515}$ & [79] \\
\hline Ratio Analysis of Reflectance Spectra & RARS & [80] \\
\hline Carotenoid Reflectance Index 1 & CRI1 & [81] \\
\hline \multicolumn{3}{|l|}{ Anthocyanin } \\
\hline Anthocyanin Reflectance Index & ARI & [82] \\
\hline Anthocyanin Reflectance Index 2 & ARI2 & [81] \\
\hline \multicolumn{3}{|l|}{ Xanthophyll } \\
\hline Photochemical Reflectance Index (570) & PRI570 & [83] \\
\hline Photochemical Reflectance Index (515) & PRI515 & {$[84]$} \\
\hline \multicolumn{3}{|l|}{ Water } \\
\hline Moisture Stress Index & MSI & [85] \\
\hline Water Index & $W I$ & [86] \\
\hline \multicolumn{3}{|l|}{ Tree Structure } \\
\hline Simple Ratio & $S R$ & [87] \\
\hline Soil Adjusted Vegetation Index & SAVI & [88] \\
\hline Atmospherically Resistant Vegetation Index & $A R V I$ & [89] \\
\hline Enhanced Vegetation Index & $E V I$ & {$[90]$} \\
\hline Visible Atmospherically Resistant Index & VARI & [91] \\
\hline Vegetation Index using Green Band & VIgreen & [91] \\
\hline Standardized LAI Determining Index & sLAIDi & [92] \\
\hline Spectral index developed using the OMNBR approach & ILAI & [46] \\
\hline Renormalized Difference Vegetation Index & $R D V I$ & [93] \\
\hline Modified Simple Ratio & MSR & [94] \\
\hline Optimized Soil-Adjusted Vegetation Index & OSAVI & [77] \\
\hline
\end{tabular}


Table 3. Cont.

\begin{tabular}{|c|c|c|}
\hline Spectral Indices Related to & Abbreviation & Reference \\
\hline Modified Soil-Adjusted Vegetation Index & MSAVI & [95] \\
\hline Modified Triangular Vegetation Index 1 & MTVI1 & [96] \\
\hline Modified Triangular Vegetation Index 2 & MTVI2 & [96] \\
\hline Modified Chlorophyll Absorption Ratio Index 1 & MSAVI1 & [96] \\
\hline Modified Chlorophyll Absorption Ratio Index 2 & MSAVI2 & [96] \\
\hline Lichtenthaler Index & LIC1 & [97] \\
\hline \multicolumn{3}{|l|}{ Others } \\
\hline Redness Index & $R$ & [98] \\
\hline Greenness Index & G & [99] \\
\hline Red/Green Index & RGI & [100] \\
\hline Ratio Index & Br625_795 & [101] \\
\hline Healthy-Index & $H \bar{I}$ & [102] \\
\hline$(\mathrm{R} 793.8-\mathrm{R} 626.3) /(\mathrm{R} 793.8+\mathrm{R} 626.3)$ & NCR1 & [19] \\
\hline$(\mathrm{R} 772.8-\mathrm{R} 725.8) /(\mathrm{R} 772.8+\mathrm{R} 725.8)$ & NCR2 & [19] \\
\hline$(\mathrm{R} 793.8-\mathrm{R} 626.3) /(\mathrm{R} 793.8+\mathrm{R} 626.3)$ & NCR3 & [19] \\
\hline
\end{tabular}

\subsection{Random Forest Classification}

Random forest (RF), introduced by Breiman [103], is a non-parametric classifier using a bootstrapped set of training samples and subsets of input features to build a large number of classification trees, from which the final classification result is determined as a voting result. When each tree was built, one-third of training samples, called out-of-bag (OOB) samples were left out. For each OOB sample, the classification result was determined by the majority vote from the trees generated without using this sample. An RF classifier is particularly suitable for this study because (i) it has shown to perform well even when the number of features is much larger than the number of observations, (ii) it does not require normalization [104], and (iii) it returns measures of feature importance [105].

\subsubsection{Classification Scenarios}

Four classification scenarios were defined in this study. Scenarios 1-3 aimed at comparing the performance of ALS indices, HSI indices and their combination for predicting tree health. In scenario 1 (ALS models), each of the three tree health indicators (defoliation, discoloration and damage) was classified into class 0, 1, or 2 for datasets 1-3 separately (Acer spp., Aesculus spp. and Tilia spp.; cf. Section 2.2) using 140 ALS indices. This means a total of nine classification models was created in scenario 1 (three tree health indicators $\times$ three species). The same strategy was applied in scenarios 2 and 3, yet with other input indices (61 HSI indices in scenario 2 (HSI models) and all indices in scenario 3 (ALS-HSI models)). In scenario 4 (ALS-HSI mixed models), the effects of tree species mixtures on defoliation, discoloration and damage classification were examined using dataset 4 (i.e., the mixed species dataset, cf. Section 2.2) and all indices.

\subsubsection{Classification Procedure}

We used leave-one-out cross-validation (LOOCV), which was recommended for small sample sizes in previous studies (such as DREAM challenge dataset with 35 samples [106]) to train and test RF models. In LOOCV, each training set is created by taking all the samples except one, the test set being the sample left out. Therefore, for $\mathrm{n}$ samples, we had $n$ different training sets and $n$ different test sets. The distribution of the health classes in the study area was unbalanced, with healthy trees appearing more frequently than unhealthy trees (Figure A1). To avoid high omission errors of the minority class, a balanced RF classifier was applied [107]. In this way, the accuracy of majority and minority classes was equally estimated by the classifier. The two important parameters for RF classification are the number of classification trees (ntree) and the number of features selected at each split in the tree building process (mtry). ntree was set at 500 and $m$ try was set at $\operatorname{sqt}(M)$ ( $M$ being the number of input indices) based on previous work $[26,54,105]$. The classification procedure was conducted in Python using the scikit-learn library. Classification accuracy was assessed using a weighted kappa 
coefficient $(\mathrm{Kc})$ and overall accuracy $(\mathrm{OA})$ based on the predicted and observed scores of the $n$ test sets. For ordinal categories, a weighted $\mathrm{Kc}_{\mathrm{c}}$ is more meaningful as misclassification by more than one category was penalized more heavily, making the Kc values conservative $[108,109]$. Note that in scenario 4 (mixed tree species), the Kc and OA were additionally calculated for Acer spp., Aesculus spp. and Tilia spp. separately to compare with the results of scenario 3. It is worth noting that although there have been some concerns on the suitability of the Kc in accuracy assessment [110,111], such as the substantial difficulties in its interpretation, the risks of misleading by using the $\mathrm{Kc}_{\mathrm{c}}$ in the current study are low as our focus is on comparing different models using the same samples.

\subsubsection{Feature Importance and Selection}

One of the features of RF is its ability to evaluate the importance of each input feature. Here, the importance of each index was calculated using the method of average decrease in impurity (MDI), which is calculated over all trees of the ensemble [112], and is found to be more appropriate for smaller sample sizes [113]. Based on the average rank of each index in the $n$ models, important indices were identified even if they were highly correlated and performed similar functions.

Although RF can handle a large set of input features, many irrelevant input features can decrease the model accuracy, due to the overfitting problem. The process of feature selection can identify small sets of features that can still achieve good predictive performance [105]. Existing feature selection techniques can be classified as either filter approaches or wrapper approaches [114]. Filter approaches, which determine the relevance of features using training data alone, are relatively computationally cheap. Due to the relevant features being selected independently of the learning algorithm, they may, however, not match the chosen algorithm [115]. Wrapper approaches call on learning algorithms for evaluating multiple subsets of input features, are reported to produce higher accuracy than filter approaches $[115,116]$, but are computationally intensive. In this study, we used a forward selection method (a wrapper approach) in combination with the importance ranking to select the smallest set of indices that could produce the highest accuracy. The correlated indices were retained in the final classification as a preliminary test indicated decreased classification accuracies when removing the less important indices which are highly related (Pearson's correlation coefficient $>0.9$ ) to the indices with a high importance ranking. The classification accuracies reported in this study were based on the forward selection method.

\subsection{Statistical Analysis}

To examine the structural and spectral differences represented by the ALS and HSI indices between the four tree species, we conducted Tukey's HSD test for each index between healthy trees (damage score $=0$ ) of the four tree species using the module of statsmodels in Python.

\section{Results}

\subsection{Tree Crown Identification and Delineation}

According to the overlapping proportions (OPs) between the manually and automatically delineated tree crown polygons, $67 \%$ of individual tree crowns showed a good match between the two sets of polygons $\left(\mathrm{OP}_{\text {ref }}>90 \%\right.$ and $\left.\mathrm{OP}_{\text {result }}>90 \%\right)$. Twenty-three percent of tree crowns were slightly over-segmented $\left(75 \%<\mathrm{OP}_{\text {result }}<90 \%\right.$ and $\left.\mathrm{OP}_{\text {ref }}>90 \%\right)$, and $15 \%$ of tree crowns were slightly under-segmented $\left(75 \%<\mathrm{OP}_{\text {ref }}<90 \%\right.$ and $\left.\mathrm{OP}_{\text {result }}>90 \%\right)$. The accuracy assessment proved that $91 \%$ of tree crowns were properly delineated.

\subsection{Performance of ALS Indices, HSI Indices and Their Combination}

Table 4 shows the classification accuracies for individual tree species in -ALS models (scenario 1), HSI models (scenario 2) and ALS-HSI models (scenario 3). The predictive performance of ALS indices and HSI indices varied between tree species. ALS models worked better than HSI models when 
classifying tree crown defoliation and damage (i.e., combination of defoliation and discoloration) for Acer spp. and Aesculus spp., while opposite results were found for Tilia spp. In tree crown discoloration classification, ALS models performed better than HSI models for Acer spp. and Tilia spp., while HSI models produced a slightly higher accuracy for Aesculus spp. The average Kc values across the three tree species were 0.73 (ALS models) and 0.68 (HSI models) for defoliation; 0.61 (ALS models) and 0.57 (HSI models) for discoloration; and 0.72 (ALS models) and 0.64 (HSI models) for damage (Figure 3).

Table 4. Classification results in scenarios 1-3 in which Random Forest models were trained and tested using ALS indices (ALS models in scenario 1), hyperspectral imagery (HSI) indices (HSI models in scenario 2) and their combination (ALS-HSI models in scenario 3), respectively, for individual tree species (datasets 1-3, cf. Section 2.2). The highest accuracies for predicting each tree health indicator for each species are highlighted in bold.

\begin{tabular}{cccccccc}
\hline \multirow{2}{*}{$\begin{array}{c}\text { Tree } \\
\text { Health } \\
\text { Indicators }\end{array}$} & $\begin{array}{c}\text { Tree } \\
\text { Species }\end{array}$ & $\begin{array}{c}\text { Weighted Kappa Coefficients (Kc) } \\
\text { Models }\end{array}$ & $\begin{array}{c}\text { HSI } \\
\text { Models }\end{array}$ & $\begin{array}{c}\text { ALS-HSI } \\
\text { Models }\end{array}$ & $\begin{array}{c}\text { ALS } \\
\text { Models }\end{array}$ & $\begin{array}{c}\text { HSI } \\
\text { Models }\end{array}$ & $\begin{array}{c}\text { ALS-HSI } \\
\text { Models }\end{array}$ \\
\cline { 3 - 8 } Defoliation & Acer & $\mathbf{0 . 7 7}$ & 0.56 & 0.76 & 0.86 & 0.84 & $\mathbf{0 . 8 9}$ \\
& Aesculus & 0.75 & 0.70 & $\mathbf{0 . 7 7}$ & 0.82 & 0.79 & $\mathbf{0 . 8 5}$ \\
& Tilia & 0.68 & 0.77 & $\mathbf{0 . 7 8}$ & 0.79 & $\mathbf{0 . 8 6}$ & $\mathbf{0 . 8 6}$ \\
\hline \multirow{4}{*}{ Discoloration } & Acer & 0.47 & 0.42 & $\mathbf{0 . 5 3}$ & 0.78 & $\mathbf{0 . 8 1}$ & $\mathbf{0 . 8 1}$ \\
& Aesculus & 0.59 & 0.60 & $\mathbf{0 . 7 2}$ & 0.74 & 0.76 & $\mathbf{0 . 8 2}$ \\
& Tilia & 0.78 & 0.70 & $\mathbf{0 . 7 9}$ & $\mathbf{0 . 8 8}$ & 0.83 & $\mathbf{0 . 8 8}$ \\
\hline \multirow{2}{*}{ Damage } & Acer & $\mathbf{0 . 7 7}$ & 0.56 & 0.76 & 0.86 & 0.84 & $\mathbf{0 . 8 9}$ \\
& Aesculus & 0.70 & 0.60 & $\mathbf{0 . 7 7}$ & 0.79 & 0.79 & $\mathbf{0 . 8 8}$ \\
& Tilia & 0.68 & 0.77 & $\mathbf{0 . 7 8}$ & 0.79 & $\mathbf{0 . 8 6}$ & $\mathbf{0 . 8 6}$ \\
\hline
\end{tabular}

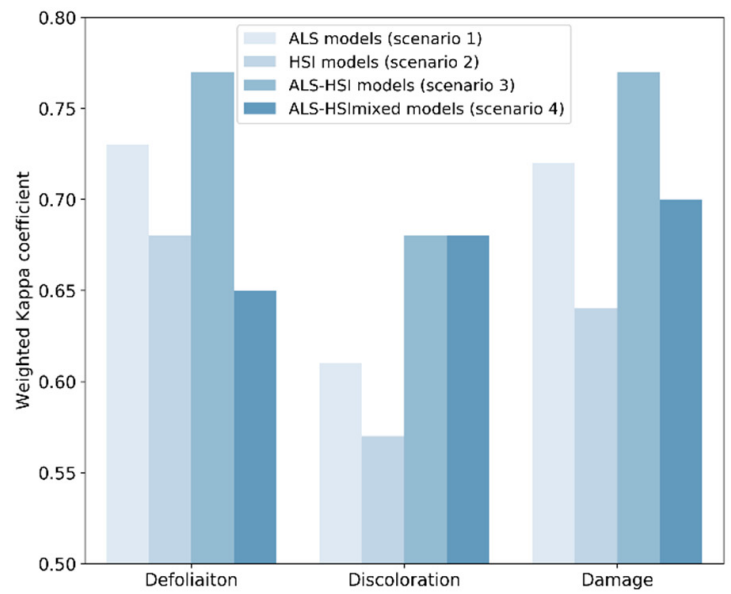

(a)

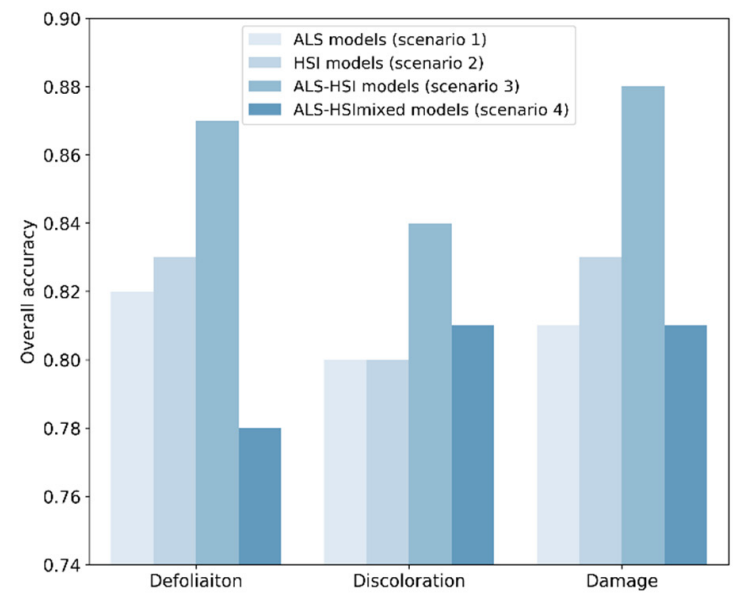

(b)

Figure 3. Classification accuracies in the four scenarios: (a) Weighted Kappa coefficient (Kc); (b) overall accuracy (OA). In scenarios 1-3, the Kc and OA for each tree health indicator were averaged for the three tree species (i.e., Acer spp., Aesculus spp. and Tilia spp.).

The average Kc values for all ALS models, HSI models and ALS-HSI models were 0.69, 0.63 and 0.74 , with OA values of $0.81,0.82$, and 0.86 , respectively (Table 4 ). For the majority of tree health indicators and tree species, the highest accuracy was obtained using ALS-HSI models. The increase in Kc points, compared with ALS models, ranged from -0.01 to 0.13 with an average of 0.05 , and compared with HSI models from 0.01 to 0.20 with an average of 0.11 . The average Kc values for the ALS-HSI models for tree crown defoliation, discoloration and damage classification were $0.77,0.68$, and 0.77 , respectively, and the corresponding $\mathrm{OA}$ values were $0.87,0.84$, and 0.88 , respectively (Figure 3 ). When considering the performance of ALS-HSI models between tree species, the health condition 
of Tilia trees was best predicted (average $\mathrm{Kc}=0.78$ for the three tree health indicators), followed by Aesculus trees (average $\mathrm{Kc}=0.75$ for the three tree health indicators) and Acer trees (average Kc $=0.68$ for the three tree health indicators) (Table 4).

\subsection{Tree Health Classification for Mixed Species}

Recall that scenario 4 differed from scenario 3 (ALS-HSI models) in that way that in scenario 3 the classification was performed on individual species. Scenario 4, in which the combination of ALS and HSI indices was used to train and test tree health classification models for the combination

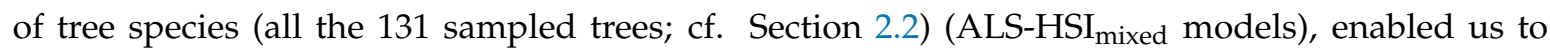
examine the effect of mixed species on tree health classification. The final Kc values for defoliation, discoloration and damage were $0.65,0.68$, and 0.70 with corresponding $\mathrm{OA}$ values of $0.78,0.81$, and 0.81 , respectively (Figure 3). The Kc and OA values calculated for individual species in ALS-HSI mixed $_{1}$ models were compared with their counterparts in scenario 3 (Figure 4). ALS-HSI models calibrated per tree species almost systematically outperformed the ALS-HSI mixed models, with an average increase in Kc points of 0.15, 0.03, and 0.05 for Acer spp., Aesculus spp., and Tilia spp., respectively. When focusing on the tree health indicators, the highest average increase in Kc points $(0.12)$ was found for defoliation, followed by damage (0.09) and discoloration (0.01).

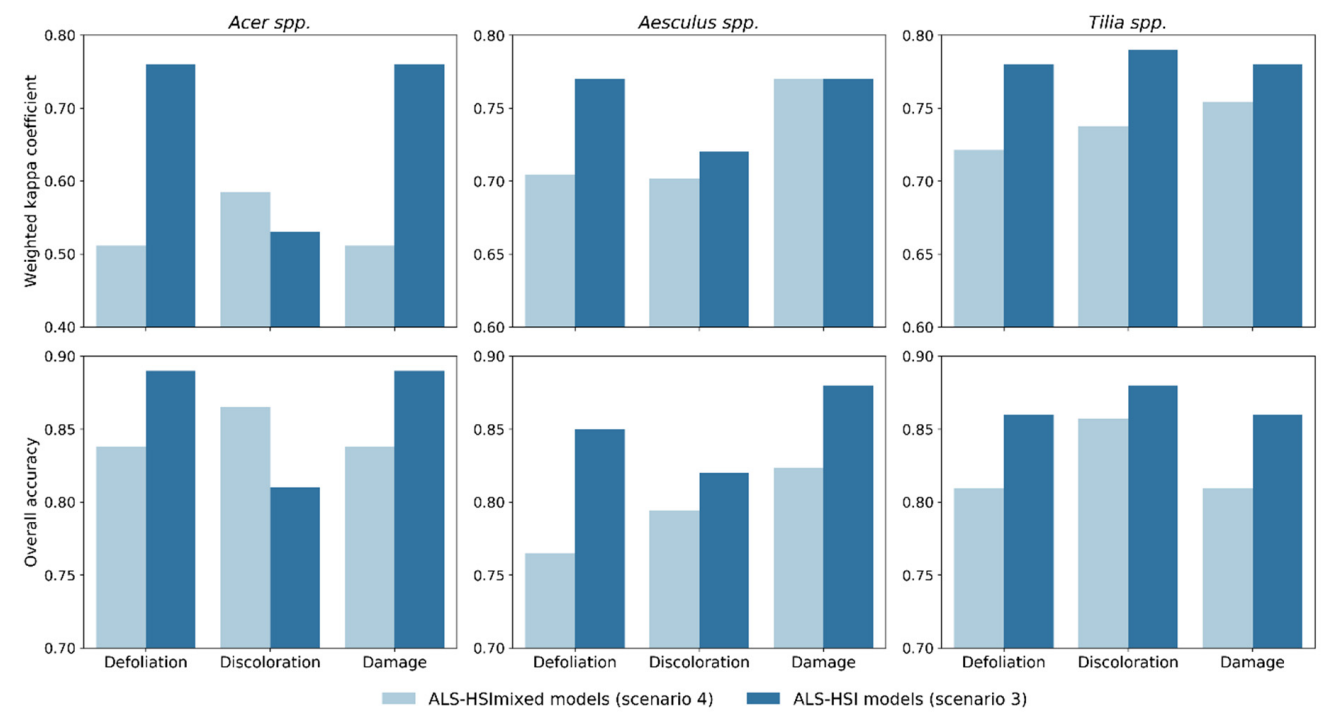

Figure 4. Comparison of tree health classification accuracy for individual species between ALS-HSI models in scenario 3 (models trained and tested for individual tree species using both ALS and HSI indices) and ALS-HSI mixed models in scenario 4 (models trained and tested for mixed tree species using both ALS and HSI indices).

\subsection{Feature Importance}

Table 5 shows the 17 most important indices (a maximum of 17 indices was required to achieve the best classification accuracy) determined by the MDI method in the ALS-HSI models and ALS-HSI mixed $_{\text {. }}$ models for tree crown defoliation, discoloration and damage classification. The importance ranking of indices varied considerably between tree species. The ALS indices that appeared most frequently in the 17 most important indices were those related to the ALS point density (i.e., $F G$ and $F C$ in 10 models, $D E N$ and $E W I$ in seven models and GT in five models), tree size, and shape (i.e., $W H, R C H V H$, and $C D$ in nine models and $C A$ in seven models). The height and intensity indices did not significantly contribute to tree health classification. The most important HSI indices were associated with spectral features of chlorophyll absorption (e.g., CCI in eight models, VOG1 and VOG2 in seven models, REP in six models and ICHL, DattNIRCabCx $+c$ and MTCI in five models) and leaf area index (i.e., ILAI in six models). 
Table 5. The 17 most important indices in ALS-HSI models (scenario 3; Acer, Aesculus and Tilia) and ALS-HSI mixed models (scenario 4; Mixed) for tree crown defoliation, discoloration and damage (i.e., combination of defoliation and discoloration) classification. ALS indices were underlined to distinguish them from HSI indices. The indices used in the final classification models (according to the forward selection method; cf. Section 2.6.3) are highlighted in bold. The explanation of the index abbreviations can be found in Tables 2 and 3.

\begin{tabular}{|c|c|c|c|c|c|c|c|c|c|c|c|c|}
\hline \multirow{2}{*}{$\begin{array}{c}\text { Importance } \\
\text { Ranking }\end{array}$} & \multicolumn{4}{|c|}{ Defoliation } & \multicolumn{4}{|c|}{ Discoloration } & \multicolumn{4}{|c|}{ Damage } \\
\hline & Acer & Aesculus & Tilia & Mixed & Acer & Aesculus & Tilia & Mixed & Acer & Aesculus & Tilia & Mixed \\
\hline 1 & $E W I$ & RARS & $\underline{F C}$ & $\underline{C D}$ & $\underline{C D}$ & ILAI & VOG2 & $\underline{C D}$ & $E W I$ & MSI & $\underline{F C}$ & $\underline{C D}$ \\
\hline 2 & $\overline{\overline{D E N}}$ & $\underline{C A}$ & $\overline{R E P}$ & $\underline{R \overline{C H V}}$ & $\overline{\overline{W H}}$ & $\underline{D E N}$ & $R E P$ & $\underline{R \overline{C H V} H}$ & $\overline{\overline{D E N}}$ & $\underline{W H}$ & $\overline{R E P}$ & $\underline{R \overline{C H V}}$ \\
\hline 3 & $\begin{array}{c}\text { DattNIRC } a b C x \\
+c\end{array}$ & $\underline{H m 50 \_60 n}$ & $C C I$ & $\overline{\underline{W H}}$ & $\underline{\mathrm{RCHVH}}$ & MSI & $\underline{E W I}$ & $\underline{W H}$ & $\begin{array}{l}\text { DattNIRCabCx } \\
+c\end{array}$ & $\underline{\mathrm{RCHVH}}$ & $C C I$ & $\underline{F C}$ \\
\hline 4 & WH & $M S R$ & $\underline{F G}$ & $\underline{F C}$ & $\underline{C A}$ & $\underline{C D}$ & $C C I$ & MTCI & $\underline{W H}$ & $\underline{C D}$ & $\underline{F G}$ & VOG2 \\
\hline 5 & $\underline{R \overline{C H V}} H$ & PSSR $a$ & $\overline{Z M}$ & $\overline{\underline{F G}}$ & $\underline{I m \overline{70 \_} 80 n}$ & $\underline{R \overline{C H V} H}$ & VOG3 & $R E P$ & $\underline{R \overline{C H V} H}$ & $\overline{\overline{C A}}$ & $\overline{Z M}$ & $\underline{W H}$ \\
\hline 6 & $\underline{C D}$ & $\underline{F G}$ & NCR1 & $\begin{array}{c}\text { DattNIRCabCx } \\
+c\end{array}$ & $\overline{\underline{D E N}}$ & GNDVI & NDRE & $\underline{C A}$ & $\underline{C D}$ & $\overline{A R V I}$ & NCR2 & $\underline{F G}$ \\
\hline 7 & PSRI & PSRRc & VOG1 & VOG1 & $\begin{array}{c}\text { DattNIRCabCx } \\
+c\end{array}$ & $\underline{W H}$ & $\underline{F G}$ & VOG1 & PSRI & $\underline{F G}$ & VOG2 & VOG3 \\
\hline 8 & MTVI1 & NCR1 & GM1 & $C C I$ & Hf 10 & $\underline{C A}$ & $\underline{F C}$ & VOG2 & MTVI1 & GM2 & GM2 & $C C I$ \\
\hline 9 & GNDVI & VOG1 & ICHL & $G T$ & $\overline{E W I}$ & $R \overline{A R S}$ & $N \overline{C R} 2$ & $D E N$ & GNDVI & VOG2 & ICHL & NCR2 \\
\hline 10 & $\underline{C A}$ & $\underline{H m 40 \_50 n}$ & $C I$ & $\overline{R E P}$ & $\overline{I m i n}$ & ARI2 & MTCI & $\overline{\underline{G T}}$ & $\underline{C A}$ & NCR1 & $C I$ & $R E P$ \\
\hline 11 & $\overline{\operatorname{VAR} I}$ & $\overline{R C H V H}$ & NAOC & NCR1 & $\overline{H p 10}$ & $\underline{F G}$ & $I L A I$ & $\overline{C C I}$ & $\overline{\operatorname{VAR} I}$ & HI & NAOC & $Z M$ \\
\hline 12 & PSSRb & $\underline{\underline{C D}}$ & $\underline{C T}$ & $\underline{\text { Iipr }}$ & $\overline{\text { If20 }}$ & $\overline{N C R} 2$ & $\underline{D E N}$ & $\underline{F C}$ & $P S S R b$ & $\underline{F C}$ & $\underline{C T}$ & ICHL \\
\hline 13 & TCARI & $\overline{F C}$ & $\overline{M T C I}$ & $\overline{V O G} 2$ & $\overline{T C A R I}$ & $\underline{E W I}$ & $\overline{\text { Iravg }}$ & $\overline{N C R 2}$ & TCARI & $\overline{V O G 1}$ & $\overline{M T C I}$ & MTCI \\
\hline 14 & CCI & MSI & $I L A I$ & $\underline{E W I}$ & $\underline{F C}$ & $\underline{H m 60 \_70 n}$ & GM2 & ICHL & $C C I$ & RARS & ILAI & $\begin{array}{l}\text { DattNIRCabCx } \\
+c\end{array}$ \\
\hline 15 & CARI & $\underline{W H}$ & VOG2 & ILAI & $\underline{F G}$ & VOG1 & VOG1 & $\underline{F G}$ & CARI & Iran & VOG3 & $\underline{G T}$ \\
\hline 16 & MCARI & $\overline{L I C 1}$ & NDRE & DEN & $\overline{G M} 2$ & $\underline{F C}$ & ICHL & $\overline{E W I}$ & MCARI & $P \overline{R I 570}$ & NDRE & $\overline{C I}$ \\
\hline 17 & Im80_90 & Hm60_70n & $\underline{G T}$ & $\overline{H p 15}$ & MCARI & $P S R R C$ & Im70_80n & $C I$ & Im80_90 & NCR2 & $\underline{G T}$ & ILAI \\
\hline
\end{tabular}


In an attempt to identify the most consistent indices across tree species, we found that in ALS models (scenario 1) EWI, $F G$, and $F C$ were important for all the three tree species for tree crown defoliation classification; $D E N, E W I, F G$, and $F C$ were consistently important for discoloration and damage classification (Table A1). When HSI indices alone were used for classification (HSI models; scenario 2), the consistently important indices were: MTCI and VOG3 for defoliation; MTCI, REP, and $\mathrm{HI}$ for discoloration; REP and VOG3 for damage (Table A2). In ALS-HSI models (scenario 3), the consistent indices across species for discoloration classification included $F C, D E N, F G$, and $E W I$ (Table 5). No consistent indices were found for defoliation and damage in this case.

\section{Discussion}

\subsection{Data and Feature Selection for Urban Tree Health Assessment}

For urban tree health assessment, selection of proper remote sensing data is crucial. However, few studies have conducted comparison between data types for tree health assessment across different tree health indicators. Our results show that ALS models outperformed HSI models in six out of the nine classifications (Table 4), which seems to indicate a better performance of ALS models. Tree crown defoliation, related to the amount of within-canopy gaps, increases penetration of ALS pulses through tree canopies and subsequently results in a greater portion of ground returns $[59,117]$. In our study, the good performance of ALS indices for defoliation classification, especially for Acer spp. and Aesculus spp., corroborates results of previous studies in which ALS was found to be robust in detecting fire- and insect-induced leaf loss in forest canopies [26,29,118]. According to the MDI method, FC, $F G$, and EWI which are all related to the ALS point density (Table 2), were consistently important across different species (Table A1), which confirms the usefulness of these ALS indices in modeling defoliation. EWI was also found to be able to explain the variance related to tree crown transparency in Shendryk et al. [30]. Four tree size and shape indices (i.e., $C D, C A, R C H V H$, and $W H$ ) which were calculated based on the spatial distribution of ALS points (Table 2) were also important for defoliation classification (Table 5, Table A1). This makes us argue that these indices could characterize the geometric changes, due to defoliation. Similarly, Yao et al. [119] also suggested the contribution of using these geometry-related indices in the detection of standing deadwood.

With regard to discoloration classification, ALS models were able to produce higher classification accuracy for Acer spp. and Tilia spp. and a similar accuracy for Aesculus spp. compared with HSI models (Table 4). Especially for Tilia spp., several intensity indices were selected for discoloration classification (Table A1), indicating that the radiometric properties of the target are sensitive to tree crown discoloration. However, Table A1 also shows that the selected ALS indices for discoloration classification were mainly related to point density, tree size, and shape, which are conceptually unrelated to discoloration. A plausible explanation for this phenomenon might be found in the strong positive correlation between our field assessed defoliation and discoloration scores (discoloration score equal to defoliation score for $78.6 \%$ sampled trees; Figure A1a). Also note that classification performance of discoloration based on ALS data was highest for Tilia spp., i.e., the species with the strongest correlation between defoliation and discoloration scores (discoloration score equal to defoliation score for $81 \%$ Tilia trees). Therefore, future tree health monitoring could, to some extent, rely on ALS data for discoloration prediction in case defoliation and discoloration co-exist in most tree crowns in the study area. To better understand the potential of ALS data for identifying tree crown discoloration, further analysis should be conducted on trees experiencing discoloration only. Given the lack of such trees in our datasets, such analysis was not feasible here. As for the poorer performance of HSI, which was expected to have higher predictive power for discoloration classification, it could be explained by: (i) The coarser spatial resolution compared with ALS data, and (ii) the pixels containing information on the mixture of leaves, woody materials and backgrounds thereby having lower applicability in differentiating tree crown discoloration levels for our samples with an unbalanced distribution of discoloration classes (Figure A1). 
Figure A1b shows that in our particular case study, overall tree damage scores were more driven by defoliation (damage score equal to defoliation score for $96.2 \%$ sampled trees), compared with discoloration (damage score equal to discoloration score for $81.7 \%$ sampled trees). This causal effect was also reflected in the classification accuracies, where defoliation and damage classification showed a similar pattern: ALS models outperformed HSI models for Acer spp. and Aesculus spp. but not for Tilia spp. (Table 4). Note that the superiority of ALS models for tree damage classification is likely to be strongly case-specific. It should be further investigated whether the same conclusion would be reached in a case where tree health is mostly driven by leaf discoloration. Due to the strong correlation between defoliation and the other two tree health indicators, we found the ALS indices important for discoloration and damage classification to show large overlap with those for defoliation (Table 5; Table A1).

Our results show that the overall highest level of accuracy was achieved in ALS-HSI models (average $\mathrm{Kc}=0.74$ and $\mathrm{OA}=0.86$; Table 4 ), highlighting the complementarity of ALS and HSI data for tree health assessment and supporting earlier findings from Shendryk et al. [30] and Meng et al. [29]. Tree health is reflected by both structure and foliar chemistry, especially pigment content, the latter known to be strongly associated with tree crown reflectance properties $[21,23]$. By explicitly providing this reflectance information by means of HSI, tree health classification was improved from an average Kc of 0.69 (only ALS data) to 0.74 (combination of ALS and HSI). This was highlighted by the important HSI indices determined by the MDI method. We found most important HSI indices were associated with the chlorophyll absorption and red-edge spectral feature (e.g., CCI, VOG1, VOG2, REP, ICHL, DattNIRCabCx $+c$ and MTCI; Table 5), which supports previous studies [27-29]. The red-edge spectral region was shown in the 1980s to be sensitive to chlorophyll content [74] and ever since has been applied in research on tree health [120]. Our study confirmed that HSI indices associated with the chlorophyll absorption feature are more relevant compared to other HSI indices in identifying urban tree health [23]. In addition, ILAI, which demonstrated a good relationship with leaf area index in Degerickx et al. [46], was also an important index for predicting tree crown health (Table 5).

\subsection{Species-Specific vs. Mixed Species Modelling Approach}

By constructing both species-specific models (ALS-HSI models) and mixed species models

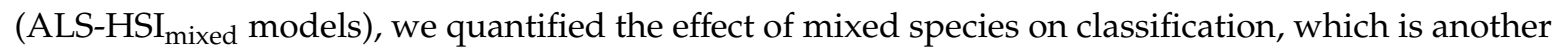
crucial issue for urban tree health assessment. Species-specific ALS-HSI models overall showed better performance than their mixed species counterparts (an average increase in Kc points of 0.07 calculated for all three tree species and tree health indicators) (Figure 4). This difference was found to be larger for Acer spp. (average increase in Kc points of 0.15 for the three tree health indicators) compared to the other tree species. To explore the underlying reasons, we conducted a Tukey's HSD test for each index between healthy trees (damage score $=0$ ) of the four tree species (Table A3). Table A3 shows that significant differences $(p<0.05)$ in indices between tree species was mainly found between Acer spp. and the other tree species, especially for HSI indices, which indicates that Acer trees observed in our study tended to have different structural and spectral characteristics from other tree species. In this context, a mixed species modelling approach would increase the possibility of misclassification for Acer spp. when using a machine learning algorithm like RF. We therefore predict that, with the increase of tree species diversity, especially with the combination of broadleaved and coniferous species, the performance of mixed species models would rapidly decrease [47]. This should, however, be further verified in follow-up research.

Given the reasoning mentioned above, it is safe to assume that in practice, a species-specific tree health mapping approach will be preferred in case of urban areas with diverse tree species. Some well-developed methods for urban tree species classification have constituted a solid basis for generating such a map. For example, Alonzo et al. [121] mapped 29 common tree species in Santa Barbara, California, USA using fused HSI and ALS data and an RF classifier, with an overall accuracy of $93.5 \%$. Although this additional classification step will undoubtedly increase the workload, the issue could be addressed by using the tree species database, which actually is already available in some 
cities. Based on such a tree species map or database, sufficient training data on tree health for each tree species should be collected in order to build a robust classification model. On the other hand, we should not ignore that some important indices (e.g., FG, FC, REP, and HI; Table A3) have the potential to be independent of tree species, which might to some extent improve the classification accuracy of a mixed species model. Future urban tree health research should take efforts to search for stable and informative indices which are not affected by tree species. The above-mentioned four indices would constitute an excellent starting point for this endeavor and should be further examined for other tree species.

\section{Conclusions}

Considering the threats of increasingly prominent urban environmental problems to tree health, frequent and accurate mapping of tree health is critical to design adaptive tree management strategies. With a complete workflow encompassing individual tree crown delineation, index calculation, feature selection, classifier training, classification and validation, we compared the performance of airborne laser scanning (ALS), airborne hyperspectral imagery (HSI), and their combination, to classify urban tree health. The combined use of both types of data produced the highest level of classification accuracy, confirming their complementarity. Overall, ALS data had better performance in predicting tree health based on our samples. However, due to the stronger dependence of damage (i.e., combination of defoliation and discoloration) scores on defoliation scores than on discoloration scores in our tree samples, the potential of ALS data for predicting damage needs to be further examined in future studies. As a reference for future research, our results highlighted that ALS indices related to point density, tree size, and shape and HSI indices associated with the chlorophyll absorption feature were most important for tree health identification. The consistently important ALS indices (i.e., DEN, EWI, FG, and FC) and HSI indices (i.e., MTCI, VOG3, REP, and HI) across the three tree species in our study, however, should be further tested for their applicability and transferability to other common tree species in an urban context.

The high heterogeneity of tree species in urban environments makes it hard to map tree health on a city scale using remote sensing technologies. In our study, a species-specific tree health modelling approach (ALS-HSI models; scenario 3) proved to yield higher accuracies overall (an average increase in Kc points of 0.07 ) compared to combining all species into one tree health model (ALS-HSI mixed models; scenario 4). Even though further research is required covering more diverse tree species settings, some practical guidelines can already be formulated based on our findings. In case a quick overview of tree health needs to be obtained over an area with limited tree species diversity, a mixed species modelling approach should be preferred-since it represents the least time-consuming approach. In that case, most attention should be devoted towards identifying ALS and HSI indices which are independent of tree species. However, in case the study area shows a highly heterogeneous tree species pool, the added value of constructing species-specific models becomes truly significant. This can be achieved by involving an available tree species database or a tree species map generated from the same remote sensing data sources.

Author Contributions: Conceptualization, D.C., K.Y. and B.S.; methodology, D.C., J.D. and K.Y.; software, D.C.; validation, D.C.; formal analysis, D.C.; investigation, J.D.; resources, J.D. and B.S.; data curation, D.C. and J.D.; writing-original draft preparation, D.C.; writing—review and editing, all authors; visualization, D.C.; supervision, K.Y.; project administration, D.C.; funding acquisition, B.S. All authors have read and agreed to the published version of the manuscript.

Funding: This research was funded by the Belgian Science Policy Office in the framework of the STEREOIII program (UrbanEARS project (SR/00/307) and BelAir project (SR/01/354)). In addition, the authors acknowledge financial support from the China Scholarship Council.

Conflicts of Interest: The authors declare no conflict of interest. 


\section{Appendix A}

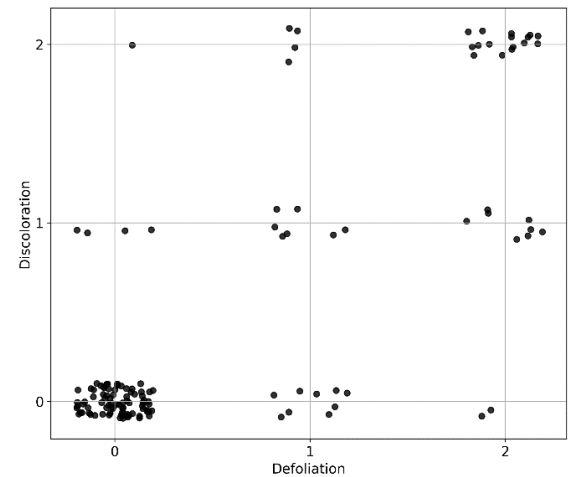

(a)

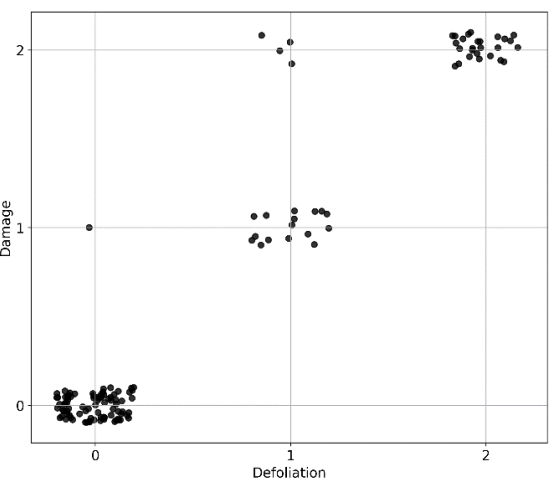

(b)

Figure A1. Distribution of tree health scores for the 131 sampled trees: (a) defoliation and discoloration scores; (b) defoliation and damage scores.

Table A1. The 17 most important indices in ALS models (scenario 1) for tree crown defoliation, discoloration and damage (i.e., combination of defoliation and discoloration) classification. The indices used in the final classification models (according to the forward selection method; Section 2.6.3) are highlighted in bold. The explanation of the indices abbreviations can be found in Table 2.

\begin{tabular}{|c|c|c|c|c|c|c|c|c|c|}
\hline \multirow{2}{*}{$\begin{array}{l}\text { Importance } \\
\text { Ranking }\end{array}$} & \multicolumn{3}{|c|}{ Defoliation } & \multicolumn{3}{|c|}{ Discoloration } & \multicolumn{3}{|c|}{ Damage } \\
\hline & Acer & Aesculus & Tilia & Acer & Aesculus & Tilia & Acer & Aesculus & Tilia \\
\hline 1 & $D E N$ & Hm40_50n & $F C$ & WH & RCHVH & EWI & DEN & $F G$ & $F C$ \\
\hline 2 & $E W I$ & $F G$ & $F G$ & RCHVH & $C D$ & $F C$ & $E W I$ & RCHVH & $F G$ \\
\hline 3 & RCHVH & Hravg & $C T$ & $C A$ & $D E N$ & $F G$ & RCHVH & WH & $C T$ \\
\hline 4 & Im80_90 & $F C^{\circ}$ & Hm10_20 & $C D$ & $E W I$ & DEN & Im80_90 & If 70 & Hm10_20 \\
\hline 5 & 190 & RCHVH & $G T^{-}$ & $D E N$ & $C A$ & Im60_70n & I $p 90$ & $C D$ & $G^{-}$ \\
\hline 6 & $F G$ & Hm50_60n & $D E N$ & EWI & WH & Нр20 & $F G$ & EWI & $D E N$ \\
\hline 7 & $C D$ & $C A$ & EWI & If 20 & $F G$ & Im50_60n & $C D$ & $C A$ & EWI \\
\hline 8 & $F C$ & Нр20 & Iske & $F G$ & Hm60_70n & Im90_100n & $F C$ & Нp 25 & Iske \\
\hline 9 & Ip85 & Hm60_70n & Hf30 & Hp10 & $F C$ & Iam & Ip85 & $F C$ & Hf30 \\
\hline 10 & WH & $E W I$ & Im60_70n & Imin & Hf 90 & Iske & WH & $\operatorname{Imax}$ & Im60_70n \\
\hline 11 & Iipr & $C D$ & Hp10 & Im70_80n & If70 & Hm10_20 & Iipr & $D E N$ & Hp10 \\
\hline 12 & $C A$ & Hm20_30 & Im70_80n & Hf10 & Hm70_80n & Hm90_100n & $C A$ & Iran & Im70_80n \\
\hline 13 & Ip 80 & $W H$ & If 30 & $F C$ & If 90 & Iravg & Ip80 & Hm60_70n & If 30 \\
\hline 14 & Im0_10n & Hf10 & Нp20 & Iran & Hravg & Im70_80n & Im0_10n & Hf10 & Нp 20 \\
\hline 15 & Ip75 & $C T$ & Ip 20 & Hm40_50n & If10 & Ikur & Ip75 & Hm20_30 & Ip 20 \\
\hline 16 & $G T$ & Hm20_30n & Ip15 & GT & Ip05 & $C T$ & $G T$ & Hm20_30n & Ip15 \\
\hline 17 & Hp15 & Hm10_20 & Im10_20 & Iravg & Hm30_40n & $I c v$ & Hp15 & Нp 20 & Im10_20 \\
\hline
\end{tabular}

Table A2. The 17 most important indices in HSI models (scenario 2) for tree crown defoliation, discoloration and damage (i.e., combination of defoliation and discoloration) classification. The indices used in the final classification models (according to the forward selection method; Section 2.6.3) are highlighted in bold. The explanation of the indices abbreviations can be found in Table 3 .

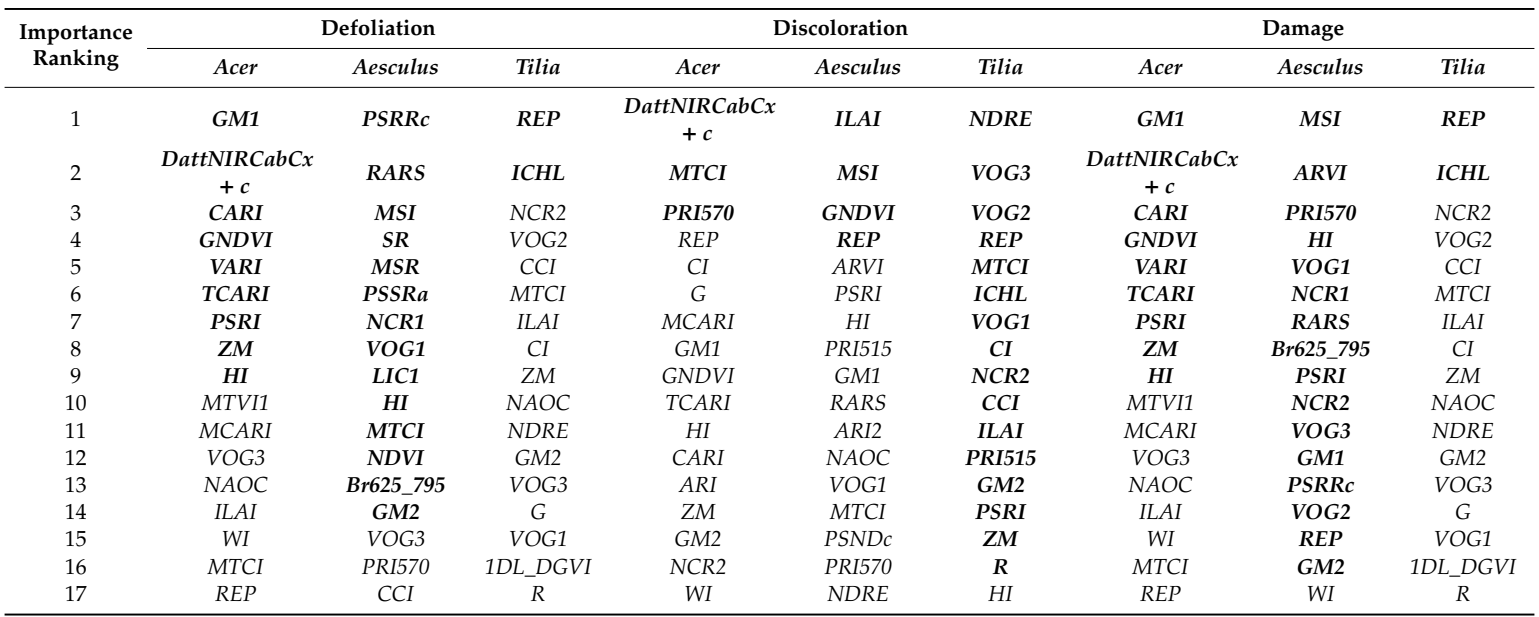


Table A3. Results of Tukey's HSD test for the indices values between healthy trees (damage score $=0$ ) of different tree species. a, b, c, and d referred to Acer spp., Aesculus spp., Platanus spp. and Tilia spp., respectively. The difference with a significance level of $p<0.05$ are marked in bold. Only the indices whose values showed significant difference between at least two tree species are listed.

\begin{tabular}{|c|c|c|c|c|c|c|c|c|c|c|c|c|c|}
\hline Indices & $\mathbf{a}-\mathbf{b}$ & $a-c$ & $a-d$ & b-c & b-d & $c-d$ & Indices & $\mathbf{a}-\mathbf{b}$ & $a-c$ & $a-d$ & b-c & b-d & $c-d$ \\
\hline Iaad & 0.200 & 0.014 & 0.247 & 0.438 & 0.900 & 0.293 & VOG3 & 0.005 & 0.033 & 0.080 & 0.900 & 0.625 & 0.683 \\
\hline$I 70$ & 0.400 & 0.040 & 0.743 & 0.479 & 0.900 & 0.189 & $Z M$ & 0.001 & 0.073 & 0.024 & 0.900 & 0.641 & 0.900 \\
\hline$I 75$ & 0.337 & 0.026 & 0.636 & 0.435 & 0.900 & 0.179 & GNDVI & 0.003 & 0.003 & 0.002 & 0.786 & 0.900 & 0.738 \\
\hline I80 & 0.269 & 0.017 & 0.485 & 0.411 & 0.900 & 0.194 & DI1 & 0.003 & 0.326 & 0.001 & 0.736 & 0.900 & 0.713 \\
\hline I85 & 0.205 & 0.013 & 0.285 & 0.423 & 0.900 & 0.257 & GOSAVI & 0.080 & 0.127 & 0.001 & 0.900 & 0.616 & 0.900 \\
\hline I90 & 0.165 & 0.010 & 0.153 & 0.428 & 0.900 & 0.334 & TCARI & 0.033 & 0.524 & 0.900 & 0.873 & 0.061 & 0.623 \\
\hline I95 & 0.138 & 0.016 & 0.060 & 0.544 & 0.900 & 0.585 & PSRRC & 0.265 & 0.048 & 0.001 & 0.623 & 0.026 & 0.740 \\
\hline Iipr & 0.352 & 0.012 & 0.675 & 0.284 & 0.900 & 0.091 & $C R I_{550} 515$ & 0.809 & 0.601 & 0.003 & 0.287 & 0.001 & 0.557 \\
\hline $\operatorname{Im} 70 \quad 80$ & 0.339 & 0.026 & 0.635 & 0.435 & 0.900 & 0.180 & CRI1 & 0.325 & 0.682 & 0.016 & 0.112 & 0.001 & 0.688 \\
\hline Im80_90 & 0.210 & 0.013 & 0.293 & 0.417 & 0.900 & 0.252 & ARI2 & 0.051 & 0.027 & 0.133 & 0.821 & 0.900 & 0.552 \\
\hline Im60_70n & 0.648 & 0.094 & 0.900 & 0.490 & 0.307 & 0.030 & PRI515 & 0.003 & 0.538 & 0.275 & 0.518 & 0.001 & 0.053 \\
\hline CNT & 0.807 & 0.048 & 0.900 & 0.236 & 0.900 & 0.112 & $S R$ & 0.359 & 0.079 & 0.001 & 0.656 & 0.011 & 0.578 \\
\hline$C A$ & 0.844 & 0.002 & 0.900 & 0.022 & 0.900 & 0.004 & $S A V I$ & 0.037 & 0.286 & 0.003 & 0.900 & 0.900 & 0.861 \\
\hline$C D$ & 0.900 & 0.003 & 0.900 & 0.021 & 0.900 & 0.005 & $A R V I$ & 0.900 & 0.093 & 0.008 & 0.172 & 0.036 & 0.900 \\
\hline WH & 0.799 & 0.003 & 0.900 & 0.034 & 0.900 & 0.007 & $E V I$ & 0.037 & 0.506 & 0.004 & 0.900 & 0.900 & 0.670 \\
\hline EWI & 0.333 & 0.002 & 0.900 & 0.088 & 0.673 & 0.007 & VARI & 0.002 & 0.828 & 0.037 & 0.213 & 0.001 & 0.038 \\
\hline RCHVH & 0.608 & 0.008 & 0.900 & 0.120 & 0.716 & 0.013 & VIgreen & 0.001 & 0.681 & 0.243 & 0.179 & 0.001 & 0.086 \\
\hline$D E N$ & 0.320 & 0.003 & 0.723 & 0.147 & 0.842 & 0.028 & $s L A I D i$ & 0.009 & 0.900 & 0.537 & 0.061 & 0.191 & 0.667 \\
\hline CARI & 0.033 & 0.882 & 0.900 & 0.533 & 0.016 & 0.760 & ILAI & 0.079 & 0.021 & 0.607 & 0.696 & 0.554 & 0.163 \\
\hline$C C I$ & 0.004 & 0.064 & 0.059 & 0.900 & 0.638 & 0.880 & $R D V I$ & 0.040 & 0.266 & 0.001 & 0.900 & 0.776 & 0.761 \\
\hline CI & 0.001 & 0.073 & 0.024 & 0.900 & 0.641 & 0.900 & $M S R$ & 0.493 & 0.059 & 0.001 & 0.500 & 0.006 & 0.655 \\
\hline 1DL_DGVI & 0.028 & 0.496 & 0.005 & 0.874 & 0.900 & 0.710 & OSAVI & 0.080 & 0.127 & 0.001 & 0.900 & 0.616 & 0.900 \\
\hline GM1 & 0.001 & 0.007 & 0.001 & 0.900 & 0.900 & 0.900 & MSAVI & 0.037 & 0.302 & 0.001 & 0.900 & 0.814 & 0.736 \\
\hline GM2 & 0.001 & 0.043 & 0.001 & 0.900 & 0.900 & 0.900 & MTVI1 & 0.165 & 0.760 & 0.006 & 0.900 & 0.728 & 0.491 \\
\hline MTCI & 0.005 & 0.338 & 0.304 & 0.769 & 0.262 & 0.900 & MTVI2 & 0.310 & 0.458 & 0.001 & 0.900 & 0.204 & 0.517 \\
\hline MCARI & 0.033 & 0.524 & 0.900 & 0.873 & 0.061 & 0.623 & MSAVI1 & 0.165 & 0.760 & 0.006 & 0.900 & 0.728 & 0.491 \\
\hline$N A O C$ & 0.119 & 0.019 & 0.073 & 0.601 & 0.900 & 0.581 & MSAVI2 & 0.310 & 0.458 & 0.001 & 0.900 & 0.204 & 0.517 \\
\hline NDRE & 0.008 & 0.072 & 0.266 & 0.900 & 0.404 & 0.626 & LIC1 & 0.900 & 0.026 & 0.003 & 0.103 & 0.041 & 0.900 \\
\hline NDVI & 0.900 & 0.024 & 0.005 & 0.085 & 0.050 & 0.900 & $R$ & 0.001 & 0.895 & 0.008 & 0.003 & 0.001 & 0.378 \\
\hline ICHL & 0.017 & 0.022 & 0.267 & 0.900 & 0.543 & 0.362 & G & 0.001 & 0.509 & 0.358 & 0.051 & 0.001 & 0.062 \\
\hline$P S N D c$ & 0.809 & 0.008 & 0.007 & 0.063 & 0.136 & 0.746 & RGI & 0.006 & 0.372 & 0.271 & 0.772 & 0.001 & 0.025 \\
\hline PSSRa & 0.354 & 0.078 & 0.001 & 0.659 & 0.013 & 0.593 & Br625_795 & 0.452 & 0.023 & 0.006 & 0.325 & 0.380 & 0.900 \\
\hline PSSRb & 0.041 & 0.030 & 0.001 & 0.878 & 0.084 & 0.675 & NCR1 & 0.332 & 0.028 & 0.001 & 0.456 & 0.268 & 0.900 \\
\hline DattNIRCabCx+c & 0.003 & 0.008 & 0.001 & 0.900 & 0.439 & 0.900 & NCR2 & 0.014 & 0.036 & 0.278 & 0.900 & 0.484 & 0.458 \\
\hline VOG1 & 0.001 & 0.104 & 0.074 & 0.900 & 0.415 & 0.900 & NCR3 & 0.044 & 0.856 & 0.007 & 0.601 & 0.001 & 0.014 \\
\hline VOG2 & 0.007 & 0.029 & 0.113 & 0.900 & 0.610 & 0.600 & & & & & & & \\
\hline
\end{tabular}

\section{References}

1. Mullaney, J.; Lucke, T.; Trueman, S.J. A review of benefits and challenges in growing street trees in paved urban environments. Landsc. Urban. Plan. 2015, 134, 157-166. [CrossRef]

2. Roy, S.; Byrne, J.; Pickering, C. A systematic quantitative review of urban tree benefits, costs, and assessment methods across cities in different climatic zones. Urban. For. Urban. Green. 2012, 11, 351-363. [CrossRef]

3. Pataki, D.E.; Carreiro, M.M.; Cherrier, J.; Grulke, N.E.; Jennings, V.; Pincetl, S.; Whitlow, T.; Zipperer, W.C. Coupling biogeochemical cycles in urban environments: Ecosystem services, green solutions, and misconceptions. Front. Ecol. Environ. 2011, 9, 27-36. [CrossRef]

4. Just, M.G.; Dale, A.G.; Long, L.C.; Frank, S.D. Urbanization drives unique latitudinal patterns of insect herbivory and tree condition. Oikos 2019, 128, 984-993. [CrossRef]

5. Peñuelas, J.; Canadell, J.G.; Ogaya, R. Increased water-use efficiency during the 20th century did not translate into enhanced tree growth. Glob. Ecol. Biogeogr. 2011, 20, 597-608. [CrossRef]

6. Morgenroth, J.; Buchan, G.D. Soil moisture and aeration beneath pervious and impervious pavements. Arboric. Urban. For. 2009, 35, 135-141.

7. Clark, J.R.; Kjelgren, R. Water as a limiting factor in the development of urban trees. J. Arboric. 1990, 16, 203-208.

8. Dale, A.G.; Frank, S.D. Warming and drought combine to increase pest insect fitness on urban trees. PLoS ONE 2017, 12, e0173844. [CrossRef] 
9. Yu, K.; Van Geel, M.; Ceulemans, T.; Geerts, W.; Ramos, M.M.; Sousa, N.; Castro, P.M.L.; Kastendeuch, P.; Najjar, G.; Ameglio, T.; et al. Foliar optical traits indicate that sealed planting conditions negatively affect urban tree health. Ecol. Indic. 2018, 95, 895-906. [CrossRef]

10. Kozlowski, T.T. Soil compaction and growth of Woody plants. Scand. J. For. Res. 1999, 14, 596-619. [CrossRef]

11. Panagos, P.; Van Liedekerke, M.; Yigini, Y.; Montanarella, L. Contaminated Sites in Europe: Review of the Current Situation Based on Data Collected through a European Network. J. Environ. Public Health 2013, 2013, 158764. [CrossRef] [PubMed]

12. Tóth, G.; Hermann, T.; Da Silva, M.R.; Montanarella, L. Heavy metals in agricultural soils of the European Union with implications for food safety. Environ. Int. 2016, 88, 299-309. [CrossRef] [PubMed]

13. Yu, K.; Van Geel, M.; Ceulemans, T.; Geerts, W.; Ramos, M.M.; Serafim, C.; Sousa, N.; Castro, P.M.L.; Kastendeuch, P.; Najjar, G.; et al. Vegetation reflectance spectroscopy for biomonitoring of heavy metal pollution in urban soils. Environ. Pollut. 2018, 243, 1912-1922. [CrossRef] [PubMed]

14. Ainsworth, E.A.; Yendrek, C.R.; Sitch, S.; Collins, W.J.; Emberson, L.D. The effects of tropospheric ozone on net primary productivity and implications for climate change. Annu. Rev. Plant. Biol. 2012, 63, 637-661. [CrossRef]

15. Beck, I.; Jochner, S.; Gilles, S.; McIntyre, M.; Buters, J.T.M.; Schmidt-Weber, C.; Behrendt, H.; Ring, J.; Menzel, A.; Traidl-Hoffmann, C. High environmental ozone levels lead to enhanced allergenicity of birch pollen. PLOS ONE 2013, 8, e80147. [CrossRef]

16. Gratani, L.; Crescente, M.F.; Petruzzi, C. Relationship between leaf life-span and photosynthetic activity of Quercus ilex in polluted urban areas (Rome). Environ. Pollut. 2000, 110, 19-28. [CrossRef]

17. Hasan, R.; Othman, N.; Ismail, F. Roadside tree management in selected local authorities for public safety. Procedia. Soc. Behav. Sci. 2016, 234, 218-227. [CrossRef]

18. Lonsdale, D. Principles of Tree Hazard Assessment and Management; Stationery Office Ltd., Publications Centre: London, UK, 1999.

19. Näsi, R.; Honkavaara, E.; Blomqvist, M.; Lyytikäinen-Saarenmaa, P.; Hakala, T.; Viljanen, N.; Kantola, T.; Holopainen, M. Remote sensing of bark beetle damage in urban forests at individual tree level using a novel hyperspectral camera from UAV and aircraft. Urban. For. Urban. Green. 2018, 30, 72-83. [CrossRef]

20. Fink, S. Hazard tree identification by visual tree assessment (VTA): Scientifically solid and practically approved. Arboric. J. 2009, 32, 139-155. [CrossRef]

21. Solberg, S.; Næsset, E.; Lange, H.; Bollandsås, O.M. Remote Sensing of Forest Health. Int. Arch. Photogramm. Remote Sens. Spat. Inf. Sci. 2004, 36, W2.

22. Lakatos, F.; Mirtchev, S.; Mehmeti, A.; Shabanaj, H. Manual for Visual Assessment of Forest Crown Condition; FAO: Rome, Italy, 2014.

23. Rossini, M.; Panigada, C.; Meroni, M.; Colombo, R. Assessment of oak forest condition based on leaf biochemical variables and chlorophyll fluorescence. Tree Physiol. 2006, 26, 1487-1496. [CrossRef] [PubMed]

24. Smith, D.; Smith, I.; Collett, N.; Elms, S. Forest health surveillance in Victoria. Aust. Forest. 2008, 71, $188-195$. [CrossRef]

25. Stone, C.; Coops, N.C. Assessment and monitoring of damage from insects in Australian eucalypt forests and commercial plantations. Aust. J. Entomol. 2004, 43, 283-292. [CrossRef]

26. Barnes, C.; Balzter, H.; Barrett, K.; Eddy, J.; Milner, S.; Suárez, J.C. Airborne laser scanning and tree crown fragmentation metrics for the assessment of Phytophthora ramorum infected larch forest stands. For. Ecol. Manag. 2017, 404, 294-305. [CrossRef]

27. Fassnacht, F.E.; Latifi, H.; Ghosh, A.; Joshi, P.K.; Koch, B. Assessing the potential of hyperspectral imagery to map bark beetle-induced tree mortality. Remote Sens. Environ. 2014, 140, 533-548. [CrossRef]

28. Lausch, A.; Heurich, M.; Gordalla, D.; Dobner, H.-J.; Gwillym-Margianto, S.; Salbach, C. Forecasting potential bark beetle outbreaks based on spruce forest vitality using hyperspectral remote-sensing techniques at different scales. For. Ecol. Manag. 2013, 308, 76-89. [CrossRef]

29. Meng, R.; Dennison, P.E.; Zhao, F.; Shendryk, L.; Rickert, A.; Hanavan, R.P.; Cook, B.D.; Serbin, S.P. Mapping canopy defoliation by herbivorous insects at the individual tree level using bi-temporal airborne imaging spectroscopy and LiDAR measurements. Remote Sens. Environ. 2018, 215, 170-183. [CrossRef]

30. Shendryk, I.; Broich, M.; Tulbure, M.G.; McGrath, A.; Keith, D.; Alexandrov, S.V. Mapping individual tree health using full-waveform airborne laser scans and imaging spectroscopy: A case study for a floodplain eucalypt forest. Remote Sens. Environ. 2016, 187, 202-217. [CrossRef] 
31. Coops, N.C.; Johnson, M.; Wulder, M.A.; White, J.C. Assessment of quickbird high spatial resolution imagery to detect red attack damage due to mountain pine beetle infestation. Remote Sens. Environ. 2006, 103, 67-80. [CrossRef]

32. Dennison, P.E.; Brunelle, A.R.; Carter, V.A. Assessing canopy mortality during a mountain pine beetle outbreak using GeoEye-1 high spatial resolution satellite data. Remote Sens. Environ. 2010, 114, 2431-2435. [CrossRef]

33. Hicke, J.A.; Logan, J. Mapping white bark pine mortality caused by a mountain pine beetle outbreak with high spatial resolution satellite imagery. Int. J. Remote Sens. 2009, 30, 4427-4441. [CrossRef]

34. Stone, C.; Penman, T.; Turner, R. Managing drought-induced mortality in Pinus radiata plantations under climate change conditions: A local approach using digital camera data. For. Ecol. Manag. 2012, 265, 94-101. [CrossRef]

35. Evans, B.; Lyons, T.J.; Barber, P.A.; Stone, C.; Hardy, G. Dieback classification modelling using high-resolution digital multispectral imagery and in situ assessments of crown condition. Remote Sens. Lett. 2012, 3, 541-550. [CrossRef]

36. Hanavan, R.P.; Pontius, J.; Hallett, R. A 10-year assessment of hemlock decline in the Catskill mountain region of New York state using hyperspectral remote sensing techniques. J. Econ. Entomol. 2015, 108, 339-349. [CrossRef]

37. López-López, M.; Calderón, R.; González-Dugo, V.; Zarco-Tejada, P.J.; Fereres, E. Early Detection and Quantification of Almond Red Leaf Blotch Using High-Resolution Hyperspectral and Thermal Imagery. Remote Sens. 2016, 8, 276. [CrossRef]

38. Näsi, R.; Honkavaara, E.; Lyytikäinen-Saarenmaa, P.; Blomqvist, M.; Litkey, P.; Hakala, T.; Viljanen, N.; Kantola, T.; Tanhuanpää, T.; Holopainen, M. Using UAV-based photogrammetry and hyperspectral imaging for mapping bark beetle damage at tree level. Remote Sens. 2015, 7, 15467-15493. [CrossRef]

39. Somers, B.; Verbesselt, J.; Ampe, E.M.; Sims, N.; Verstraeten, W.W.; Coppin, P. Spectral mixture analysis to monitor defoliation in mixed-aged Eucalyptus globulus Labill plantations in southern Australia using Landsat 5-TM and EO-1 Hyperion data. Int. J. Appl. Earth Obs. Geoinf. 2010, 12, 270-277. [CrossRef]

40. Kantola, T.; Vastaranta, M.; Yu, X.; Lyytikainen-Saarenmaa, P.; Holopainen, M.; Talvitie, M.; Kaasalainen, S.; Solberg, S.; Hyyppa, J. Classification of defoliated trees using tree-level airborne laser scanning data combined with aerial images. Remote Sens. 2010, 2, 2665-2679. [CrossRef]

41. Solberg, S.; Naesset, E.; Hanssen, K.H.; Christiansen, E. Mapping defoliation during a severe insect attack on Scots pine using airborne laser scanning. Remote Sens. Environ. 2006, 102, 364-376. [CrossRef]

42. Vastaranta, M.; Kantola, T.; Lyytikäinen-Saarenmaa, P.; Holopainen, M.; Kankare, V.; Wulder, M.A.; Hyyppä, J.; Hyyppä, H. Area-based mapping of defoliation of Scots pine stands using airborne scanning LiDAR. Remote Sens. 2013, 5, 1220-1234. [CrossRef]

43. Barnes, C.; Balzter, H.; Barrett, K.; Eddy, J.; Milner, S.; Suárez, J.C. Individual tree crown delineation from airborne laser scanning for diseased larch forest stands. Remote Sens. 2017, 9, 231. [CrossRef]

44. Brandtberg, T.; Warner, T.A.; Landenberger, R.E.; McGraw, J.B. Detection and analysis of individual leaf-off tree crowns in small footprint, high sampling density lidar data from the eastern deciduous forest in North America. Remote Sens. Environ. 2003, 85, 290-303. [CrossRef]

45. Fang, F.; McNeil, B.; Warner, T.; Dahle, G.; Eutsler, E. Street tree health from space? An evaluation using WorldView-3 data and the Washington, D.C. Street Tree Spatial Database. Urban. For. Urban. Green. 2020, 49, 126634. [CrossRef]

46. Degerickx, J.; Roberts, D.A.; McFadden, J.P.; Hermy, M.; Somers, B. Urban tree health assessment using airborne hyperspectral and LiDAR imagery. Int. J. Appl. Earth Obs. Geoinf. 2018, 73, 26-38. [CrossRef]

47. Xiao, Q.F.; McPherson, E.G. Tree health mapping with multispectral remote sensing data at UC Davis, California. Urban. Ecosyst. 2005, 8, 347-359. [CrossRef]

48. Biesemans, J.; Sterckx, S.; Knaeps, E.; Vreys, K.; Adriaensen, S.; Hooy, J. Image Processing Workflows for Airborne Remote. In Proceedings of the 5th EARSeL Work, Imaging Spectroscopy, Bruges, Belgium, 23-25 April 2007; pp. 1-14.

49. Gege, P.; Fries, J.; Haschberger, P.; Schötz, P.; Schwarzer, H.; Strobl, P.; Suhr, B.; Ulbrich, G.; Vreeling, W.J. Calibration facility for airborne imaging spectrometers. ISPRS J. Photogramm. Remote Sens. 2009, 64, 387-397. [CrossRef] 
50. Berk, A.; Anderson, G.P.; Bernstein, L.S.; Acharya, P.K.; Dothe, H.; Matthew, M.W.; Adler-Golden, S.M.; Chetwynd, J.H., Jr.; Richtsmeier, S.C.; Pukall, B.; et al. MODTRAN4 radiative transfer modeling for atmospheric correction. In Proc. SPIE 3756, Optical Spectroscopic Techniques and Instrumentation for Atmospheric and Space Research III; SPIE: Bellingham, WA, USA, 20 October 1999.

51. Sterckx, S.; Vreys, K.; Biesemans, J.; Iordache, M.-D.; Bertels, L.; Meuleman, K. Atmospheric correction of APEX hyperspectral data. Misc. Geogr. 2016, 20, 16-20. [CrossRef]

52. O'Neil-Dunne, J.; MacFaden, S.; Royar, A. A versatile, production-oriented approach to high-resolution tree-canopy mapping in urban and suburban landscapes using GEOBIA and data fusion. Remote Sens. 2014, 6, 12837-12865. [CrossRef]

53. Zhao, Y.; Hao, Y.; Zhen, Z.; Quan, Y. A Region-Based Hierarchical Cross-Section Analysis for Individual Tree Crown Delineation Using ALS Data. Remote Sens. 2017, 9, 1084. [CrossRef]

54. Kamińska, A.; Lisiewicz, M.; Stereńczak, K.; Kraszewski, B.; Sadkowski, R. Species-related single dead tree detection using multi-temporal ALS data and CIR imagery. Remote Sens. Environ. 2018, 219, 31-43. [CrossRef]

55. Coren, F.; Sterzai, P. Radiometric correction in laser scanning. Int. J. Remote Sens. 2006, 27, 3097-3104. [CrossRef]

56. Baltsavias, E.P. Airborne laser scanning: Basic relations and formulas. ISPRS J. Photogramm. Remote Sens. 1999, 54, 199-214. [CrossRef]

57. García, M.; Riaño, D.; Chuvieco, E.; Danson, F.M. Estimating biomass carbon stocks for a Mediterranean forest in central Spain using LiDAR height and intensity data. Remote Sens. Environ. 2010, 114, 816-830. [CrossRef]

58. Kato, A.; Monika Moskal, L.; Schiess, P.; Swanson, M.E.; Calhoun, D.; Stuetzle, W. Capturing tree crown formation through implicit surface reconstruction using airborne lidar data. Remote Sens. Environ. 2009, 113, 1148-1162. [CrossRef]

59. Bright, B.C.; Hudak, A.T.; McGaughey, R.; Andersen, H.-E.; Negrón, J. Predicting live and dead tree basal area of bark beetle affected forests from discrete-return lidar. Can. J. Remote. Sens. 2013, 39, S99-S111. [CrossRef]

60. Kim, S.; Mcgaughey, R.J.; Andersen, H.; Schreuder, G. Tree species differentiation using intensity data derived from leaf-on and leaf-off airborne laser scanner data. Remote Sens. Environ. 2009, 113, 1575-1586. [CrossRef]

61. Daughtry, C.S.T.; Walthall, C.L.; Kim, M.S.; de Colstoun, E.B.; McMurtrey, J.E. Estimating corn leaf chlorophyll concentration from leaf and canopy reflectance. Remote Sens. Environ. 2000, 74, 229-239. [CrossRef]

62. Coops, N.C.; Stone, C.; Culvenor, D.S.; Chisholm, L.A.; Merton, R.N. Chlorophyll content in eucalypt vegetation at the leaf and canopy scales as derived from high resolution spectral data. Tree Physiol. 2003, 23, 23-31. [CrossRef]

63. Haboudane, D.; Miller, J.R.; Tremblay, N.; Zarco-Tejada, P.J.; Dextraze, L. Integrated narrow-band vegetation indices for prediction of crop chlorophyll content for application to precision agriculture. Remote Sens. Environ. 2002, 84, 416-426. [CrossRef]

64. Elvidge, C.D.; Chen, Z. Comparison of broad-band and narrow-band red and near-infrared vegetation indices. Remote Sens. Environ. 1995, 54, 38-48. [CrossRef]

65. Gitelson, A.A.; Merzlyak, M.N. Signature analysis of leaf reflectance spectra: Algorithm development for remote sensing of chlorophyll. Int. J. Remote Sens. 1997, 18, 2691-2697. [CrossRef]

66. Dash, J.; Curran, P.J. The MERIS terrestrial chlorophyll index. Int. J. Remote Sens. 2004, 25, 5403-5413. [CrossRef]

67. Delegido, J.; Alonso, L.; González, G.; Moreno, J. Estimating chlorophyll content of crops from hyperspectral data using a normalized area over reflectance curve (NAOC). Int. J. Appl. Earth Obs. Geoinf. 2010, 12, 165-174. [CrossRef]

68. Barnes, E.M.; Clarke, T.R.; Richards, S.E.; Colaizzi, P.D.; Haberl, J.; Kostrzewski, M.; Waller, P.; Choi, C.; Riley, E.; Thompson, T.; et al. Coincident detection of crop water stress, nitrogen status and canopy density using ground based multispectral data. In Proceedings of the Fifth International Conference on Precision Agriculture, Bloomington, IN, USA, 16-19 July 2000; pp. 1-15.

69. Rouse, J.W.; Hass, R.H.; Schell, J.A.; Deering, D.W. Monitoring vegetation systems in the Great Plains with ERTS. In Proceedings of the Third Earth Resources Technology Satellite-1 Symposium, Washington, DC, USA, 10-14 December 1973; Volume 1, pp. 309-317.

70. Blackburn, G.A. Spectral indices for estimating photosynthetic pigment concentrations: A test using senescent tree leaves. Int. J. Remote Sens. 1998, 19, 657-675. [CrossRef] 
71. Datt, B. Remote sensing of chlorophyll $\mathrm{a}$, chlorophyll $\mathrm{b}$, chlorophyll $\mathrm{a}+\mathrm{b}$, and total carotenoid content in eucalyptus leaves. Remote Sens. Environ. 1998, 66, 111-121. [CrossRef]

72. Vogelmann, J.E.; Rock, B.N.; Moss, D.M. Red edge spectral measurements from sugar maple leaves. Int. J. Remote Sens. 1993, 14, 1563-1575. [CrossRef]

73. Zarco-Tejada, P.J.; Miller, J.R.; Noland, T.L.; Mohammed, G.H.; Sampson, P.H. Scaling-up and model inversion methods with narrowband optical indices for chlorophyll content estimation in closed forest canopies with hyperspectral data. IEEE Trans. Geosci. Remote Sens. 2001, 39, 1491-1507. [CrossRef]

74. Horler, D.N.H.; Dockray, M.; Barber, J. The red edge of plant leaf reflectance. Int. J. Remote Sens. 1983, 4, 273-288. [CrossRef]

75. Gitelson, A.A.; Kaufman, Y.J.; Merzlyak, M.N. Use of a green channel in remote sensing of global vegetation from EOS-MODIS. Remote Sens. Environ. 1996, 58, 289-298. [CrossRef]

76. Buschman, C.; Nagel, E. In vivo spectroscopy and internal optics of leaves as a basis for remote sensing of vegetation. Int. J. Remote Sens. 1993, 14, 711-722. [CrossRef]

77. Rondeaux, G.; Steven, M.; Baret, F. Optimization of soil-adjusted vegetation indices. Remote Sens. Environ. 1996, 55, 95-107. [CrossRef]

78. Merzlyak, M.N.; Gitelson, A.A.; Chivkunova, O.B.; Rakitin, V.Y. Non-destructive optical detection of pigment changes during leaf senescence and fruit ripening. Physiol. Plant. 1999, 106, 135-141. [CrossRef]

79. Gitelson, A.A.; Keydan, G.P.; Merzlyak, M.N. Three-band model for noninvasive estimation of chlorophyll, carotenoids, and anthocyanin contents in higher plant leaves. Geophys. Res. Lett. 2006, 33, L11402. [CrossRef]

80. Chappelle, E.W.; Kim, M.S.; McMurtrey, J.E. Ratio analysis of reflectance spectra (RARS): An algorithm for the remote estimation of the concentrations of chlorophyll $a$, chlorophyll $b$, and carotenoids in soybean leaves. Remote Sens. Environ. 1992, 39, 239-247. [CrossRef]

81. Gitelson, A.A.; Zur, Y.; Chivkunova, O.B.; Merzlyak, M.N. Assessing carotenoid content in plant leaves with reflectance spectroscopy. Photochem. Photobiol. 2002, 75, 272-281. [CrossRef]

82. Gitelson, A.A.; Merzlyak, M.N.; Chivkunova, O.B. Optical properties and nondestructive estimation of anthocyanin content in plant leaves. Photochem. Photobiol. 2001, 74, 38-45. [CrossRef]

83. Gamon, J.A.; Peñuelas, J.; Field, C.B. A narrow-wave band spectral index that tracks diurnal changes in photosynthetic efficiency. Remote Sens. Environ. 1992, 41, 35-44. [CrossRef]

84. Hernández-Clemente, R.; Navarro-Cerrillo, R.M.; Suárez, L.; Morales, F.; Zarco-Tejada, P.J. Assessing structural effects on PRI for stress detection in conifer forests. Remote Sens. Environ. 2011, 115, 2360-2375. [CrossRef]

85. Hunt, E.R.; Rock, B.N. Detection of changes in leaf water-content using near infrared and middle-infrared reflectances. Remote Sens. Environ. 1989, 30, 43-54.

86. Peñuelas, J.; Inoue, Y. Reflectance indices indicative of changes in water and pigment contents of peanut and wheat leaves. Photosynthetica 1999, 36, 355-360. [CrossRef]

87. Jordan, C.F. Derivation of leaf area index from quality of light on the forest floor. Ecology 1969, 50, $663-666$. [CrossRef]

88. Huete, A.R. A soil-adjusted vegetation index (SAVI). Remote Sens. Environ. 1988, 25, 295-309. [CrossRef]

89. Kaufman, Y.J.; Tanré, D. Atmospherically resistant vegetation index (ARVI) for EOS-MODIS. IEEE Trans. Geosci. Remote Sens. 1992, 30, 261-270. [CrossRef]

90. Huete, A.R.; Liu, H.Q.; Batchily, K.V.; Van Leeuwen, W.J.D.A. A comparison of vegetation indices over a global set of TM images for EO -MODIS. Remote Sens. Environ. 1997, 59, 440-451. [CrossRef]

91. Gitelson, A.A.; Kaufman, Y.J.; Stark, R.; Rundquist, D. Novel algorithms for remote estimation of vegetation fraction. Remote Sens. Environ. 2002, 80, 76-87. [CrossRef]

92. Delalieux, S.; Somers, B.; Hereijgers, S.; Verstraeten, W.W.; Keulemans, W.; Coppin, P. A near-infrared narrow-waveband ratio to determine leaf area index in orch-ards. Remote Sens. Environ. 2008, 112, 3762-3772. [CrossRef]

93. Rougean, J.L.; Breon, F.M. Estimating PAR absorbed by vegetation from bidirectional reflectance measurements. Remote Sens. Environ. 1995, 51, 375-384. [CrossRef]

94. Chen, J. Evaluation of vegetation indices and modified simple ratio for boreal applications. Can. J. Remote Sens. 1996, 22, 229-242. [CrossRef]

95. Qi, J.; Chehbouni, A.; Huete, A.R.; Kerr, Y.H.; Sorooshian, S. A modified soil adjusted vegetation index. Remote Sens. Environ. 1994, 48, 119-126. [CrossRef] 
96. Haboudane, D.; Miller, J.R.; Pattey, E.; Zarco-Tejada, P.J.; Strachan, I. Hyperspectral vegetation indices and novel algorithms for predicting green LAI of crop canopies: Modeling and validation in the context of precision agriculture. Remote Sens. Environ. 2004, 90, 337-352. [CrossRef]

97. Lichtenhaler, H.K.; Lang, M.; Sowinska, M.; Heisel, F.; Mieh, J.A. Detection of vegetation stress via a new high resolution fluorescence imaging system. J. Plant. Physiol. 1996, 148, 599-612. [CrossRef]

98. Gitelson, A.A.; Yacobi, Y.Z.; Schalles, J.F.; Rundquist, D.C.; Han, L.; Stark, R.; Etzion, D. Remote estimation of phytoplankton density in productive waters. Arch. Hydrobiol. 2000, 55, 121-136.

99. Calderón, R.; Navas-Cortés, J.A.; Lucena, C.; Zarco-Tejada, P.J. High-resolution airborne hyperspectral and thermal imagery for early detection of Verticillium wilt of olive using fluorescence, temperature and narrow-band spectral indices. Remote Sens. Environ. 2013, 139, 231-245. [CrossRef]

100. Zarco-Tejada, P.J.; Berjón, A.; López-Lozano, R.; Miller, J.R.; Marin, P.; Cachorro, V.; González, M.R.; de Frutos, A. Assessing vineyard condition with hyperspectral indices: Leaf and canopy reflectance simulation in a row-structured discontinuous canopy. Remote Sens. Environ. 2005, 99, 271-287. [CrossRef]

101. Carter, G.A.; Miller, R.L. Early detection of plant stress by digital imaging within narrow stress-sensitive wavebands. Remote Sens. Environ. 1994, 50, 295-302. [CrossRef]

102. Mahlein, A.K.; Rumpf, T.; Welke, P.; Dehne, H.-W.; Plümer, L.; Steiner, U.; Oerke, E.C. Development of spectral indices for detecting and identifying plant diseases. Remote Sens. Environ. 2013, 128, 21-30. [CrossRef]

103. Breiman, L. Random forests. Mach. Learn. 2001, 45, 5-32. [CrossRef]

104. Zhang, Y.; Lin, Y. The classification of environmental audio with ensemble learning. In Proceedings of the 2013 International Conference on Advanced Computer Science and Electronics Information (ICACSEI 2013), Beijing, China, 25-26 July 2013; Atlantis Press: Paris, France, 2013.

105. Díaz-Uriarte, R.; Alvarez de Andrés, S. Gene selection and classification of microarray data using random forest. BMC Bioinform. 2006, 7, 3. [CrossRef]

106. Costello, J.C.; Heiser, L.M.; Georgii, E.; Gönen, M.; Menden, M.P.; Wang, N.J.; Bansal, M.; Ammad-ud-din, M.; Hintsanen, P.; Khan, S.A.; et al. A community effort to assess and improve drug sensitivity prediction algorithms. Nat. Biotechnol. 2014, 32, 1202-1212. [CrossRef]

107. Chen, C.; Liaw, A.; Breiman, L. Using Random Forest to Learn Imbalanced Data; Department of Statistics, University of California: Berkeley, CA, USA, 2004.

108. Ben-David, A. Comparison of classification accuracy using Cohen's Weighted Kappa. Expert Syst. Appl. 2008, 34, 825-832. [CrossRef]

109. Dash, J.P.; Watt, M.S.; Pearse, G.D.; Heaphy, M.; Dungey, H.S. Assessing very high resolution UAV imagery for monitoring forest health during a simulated disease outbreak. ISPRS J. Photogramm. Remote Sens. 2017, 131, 1-14. [CrossRef]

110. Pontius, R.G., Jr.; Millones, M. Death to kappa: Birth of quantity disagreement and allocation disagreement for accuracy assessment. Int. J. Remote Sens. 2011, 32, 4407-4429. [CrossRef]

111. Foody, G.M. Explaining the unsuitability of the kappa coefficient in the assessment and comparison of the accuracy of thematic maps obtained by image classification. Remote Sens. Environ. 2020, 239, 11630. [CrossRef]

112. Mellor, A.; Haywood, A.; Stone, C.; Jones, S. The performance of random forests in an operational setting for large area sclerophyll forest classification. Remote Sens. 2013, 5, 2838-2856. [CrossRef]

113. Archer, K.J.; Kimes, R.V. Empirical characterization of random forest variable importance measures. Comput. Stat. Data Anal. 2008, 52, 2249-2260. [CrossRef]

114. Chan, J.C.W.; Paelinckx, D. Evaluation of Random Forest and Adaboost tree-based ensemble classification and spectral band selection for ecotope mapping using airborne hyperspectral imagery. Remote Sens. Environ. 2008, 112, 2999-3011. [CrossRef]

115. Zhu, Z.X.; Ong, Y.S.; Dash, M. Wrapper-filter feature selection algorithm using a memetic framework. IEEE Trans. Syst. Man Cybern. B Cybern. 2007, 37, 70-76. [CrossRef]

116. Kohavi, R.; John, G.H. Wrappers for feature subset selection. Artif. Intell. 1997, 97, 273-324. [CrossRef]

117. Coops, N.C.; Varhola, A.; Bater, C.W.; Teti, P.; Boon, S.; Goodwin, N.; Weiler, M. Assessing differences in tree and stand structure following beetle infestation using lidar data. Can. J. Remote. Sens. 2009, 35, 497-508. [CrossRef] 
118. Alonzo, M.; Morton, D.C.; Cook, B.D.; Andersen, H.-E.; Babcock, C.; Pattison, R. Patterns of Canopy and Surface Layer Consumption in a Boreal Forest Fire from Repeat Airborne Lidar. Environ. Res. Lett. 2017, 12, 065004. [CrossRef]

119. Yao, W.; Krzystek, P.; Heurich, M. Identifying standing dead trees in forest areas based on 3D single tree detection from full waveform Lidar data. In Proceedings of the ISPRS Annals of the Photogrammetry, Remote Sensing and Spatial Information Sciences, Melbourne, Australia, 25 August-1 September 2012; pp. 359-364.

120. Zarco-Tejada, P.J.; Hornero, A.; Hernández-Clemente, R.; Beck, P.S.A. Understanding the temporal dimension of the red-edge spectral region for forest decline detection using high-resolution hyperspectral and Sentinel-2a imagery. ISPRS J. Photogramm. Remote Sens. 2018, 137, 134-148. [CrossRef] [PubMed]

121. Alonzo, M.; Bookhagen, B.; Roberts, D.A. Urban tree species mapping using hyperspectral and lidar data fusion. Remote Sens. Environ. 2014, 148, 70-83. [CrossRef]

(C) 2020 by the authors. Licensee MDPI, Basel, Switzerland. This article is an open access article distributed under the terms and conditions of the Creative Commons Attribution (CC BY) license (http://creativecommons.org/licenses/by/4.0/). 